Article

\title{
Gender, Anonymity and Team: What Determines Crowdfunding Success on Kickstarter
}

\author{
Saif Ullah * and Yulin Zhou \\ Finance Department, JMSB, Concordia University, Montréal, QC H3G 1M8, Canada; zhouyulin0306@gmail.com \\ * Correspondence: saif.ullah@concordia.ca
}

Received: 9 March 2020; Accepted: 16 April 2020; Published: 21 April 2020

\begin{abstract}
Crowdfunding allows the public to donate small amounts of money to entrepreneurs through online platforms. In contrast with traditional financial institutions, this new method facilitates the financing process through direct and easy online contact between initiators and investors. Based on the data obtained from Kickstarter, the largest crowdfunding platform, we investigate 27,117 crowdfunding projects from 1 January 2015, to 30 June 2015, and we find that a crowdfunding campaign with a realistic funding goal, a suitable funding period, and more updates and interactions with investors is much more likely to be successfully funded. In addition, the different types of founders are very influential in crowdfunding outcomes. For example, females tend to be more successful than males at collecting funds. Founders in the form of teams, companies, or a specific project are also beneficial to funding outcomes.
\end{abstract}

Keywords: crowdfunding; gender; anonymity; teams

\section{Introduction}

Funding resources are crucial to businesses, especially to new and small firms. Crowdfunding — raising money online from a large number of people-has become a new external source of financing in addition to angel investments, venture capital, and banking. Howe (2006) created the term "crowdsourcing," the antecedent of crowdfunding, to explain the process that a network uses for obtaining resources, such as ideas, solutions, or contributions, for economic activities. Based on this, Lambert and Schwienbacher (2010) first used the term "crowdfunding" for small-scale projects in the music and movie industries. They were also the first to define crowdfunding as "an open call, essentially through the internet, for the provision of financial resources either in the form of donations or in exchange for some form of reward and/or voting rights" (Lambert and Schwienbacher 2010, p. 5). They clarify this process as an exchange of resources from the internet. Later, Mollick (2014, p. 2) provided a definition of crowdfunding as "the efforts by entrepreneurial individuals and groups-cultural, social, and for-profit-to fund their ventures by drawing individuals by using the internet, without standard financial intermediaries."

The internet facilitates information sharing, so that projects' owners can express their ideas in a more efficient way and investors can become informed faster. Taking advantage of online platforms, people can get their products and ideas advertised much faster and at a lower cost. Backers can also evaluate better projects and participate more in the projects they back. With the growth of crowdfunding, many online platforms have sprung up, such as Kickstarter, Indiegogo, and Circleup. Currently, more than 50 online platforms are active in the United States. Kickstarter, which launched in 2009 , is one of the most well known and most active crowdfunding platforms. Over $\$ 3.2$ billion has been pledged to Kickstarter projects, and over 10 million people have backed its projects since 2009 (based on data retrieved on 20 September 2017). The model applied by Kickstarter is called "All-or-Nothing $(\mathrm{AON}), "$ which means entrepreneurs can access funds only once the pledges exceed the capital-raising 
goal; otherwise, they keep none of the amount pledged and the backers do not get rewards. Compared with an AON model, the "Keep-it-All" model is one in which entrepreneurs can keep the all of the pledged money, regardless of whether the capital-raising goal is achieved (Cumming et al. 2015).

Although crowdfunding is expanding, empirical research in this field is insufficient. Mollick (2014) gives a sound explanation of crowdfunding dynamics based on the data from Kickstarter. Some scholars have examined the geographic effect in crowdfunding and found that the birthing location of projects strongly affects the funding outcomes (Agrawal et al. 2011; Muller et al. 2014; Mollick 2014; among others). Other researchers analyzed the factors of crowdfunding success focusing on one specific aspect, such as from the description of projects, for example, on an individual's point of view or only taking a look at non-profit organizations (NPOs). This paper covers two main aspects of crowdfunding appeals, including projects' general characteristics and founder types. We use ordinary linear regression analysis on the whole dataset to analyze the impact of projects' general characteristics, including the number of words in projects' descriptions, the length of a project, the target amount to be raised, the number of backers of each project, updates the initiator made, the number of comments on the homepage, and the number of projects created by the same initiator. In the U.S. dataset, we control for the population of projects' original location. To analyze how the types of initiators will affect the funding outcomes, we use logistical regression analysis to investigate whether founders in the form of individuals, a team, a company, and or a specific project have a significant impact. In particular, we investigate the effect of gender from the individual dataset, the effect of anonymity of the initiator, and the effect of non-profit organizations from the company dataset.

The rest of the paper is organized as follows. In Section 2, we describe the related literature and develop hypotheses. Section 3 describes and summarizes the data. Section 4 introduces our research methodology. Section 5 provides a detailed analysis of the results, Section 6 discusses the results in detail, and Section 7 concludes.

\section{Literature Review and Hypotheses Development}

Although more and more attention is being paid to crowdfunding, the literature in this newly emerging area is still embryonic, especially the empirical research. In recent years, a number of scholars have studied this field to discover the mechanism of crowdfunding. Most of the empirical analysis that has been done so far tackles the general characteristics and dynamics of crowdfunding projects.

Belleflamme et al. (2014) first offered a theoretical study of crowdfunding, comparing two models of crowdfunding: pre-ordering (reward-based) and profit sharing (equity-based). The pre-ordering form of crowdfunding means backers can pre-order the product and price discriminations are allowed between customers. In the profit-sharing model, entrepreneurs call for individuals to invest money in order to have a share of future profits or equity securities. In this case, people are more willing to apply the pre-ordering scheme if the initial capital requirement is relatively small; otherwise, they prefer the profit-sharing scheme. However, they analyzed the two models in a mutually exclusive manner. In fact, the initiators can combine the two approaches, simultaneously seeking finance on different platforms. As a result, they suggested as a direction of future study to establish a model that allows entrepreneurs to choose an optimal combination of equity-based and reward-based crowdfunding. According to Mollick (2014), the reward-based model is currently the most popular one and is mostly frequently applied by online platforms. Zhang and Chen (2019) investigate the relationship between rewards promised in the title of a project and the probability of success. They find that number of backers increases the probability of funding success.

Belleflamme et al. (2013) investigated the characteristics of individual crowdfunding practices and the determinants of their success. They hypothesized that the funding process on crowdfunding platforms is standardized and that individuals cannot customize their campaigns based on their specific needs. This line of thinking has already received great attention in the literature. Belleflamme et al. (2013) hand-collected the data that exclude initiatives launched on structured crowdfunding platforms, that is, only 44 initiatives. However, in our study, we collect data from Kickstarter, including 27,117 
projects covering 15 industries. The amount of total money raised in our data is $\$ 293,338,289$, whereas only $4,482,183$ euros was raised in their paper. As a result, it is worthier to analyze projects on these publicly known platforms, where more projects could be studied.

Frydrych et al. (2014) suggest that lower funding targets and a shorter duration signal legitimacy by setting modest, achievable expectations. In his study, Mollick (2014) provided an introduction to crowdfunding characteristics, such as the definition of crowdfunding, the goals of founders and funders, and models of projects. He used preparedness as a signal of quality, such as whether a video is included, whether updates are often provided, and how many spelling errors exist in project pitches. He also measured network size by the log of the number of Facebook friends of founders. His results show that success possibility is positively related to both the quality of projects and the personal networks of entrepreneurs. For the factor of social networks, Agrawal et al. (2011) indicated that the internet cannot eliminate the influence of the highly connected individual, that is, personal social networks. This finding is consistent with that of Nanda and Khanna (2010), who reported that cross-border social networks play a vital role for entrepreneurs in developing countries. Robertson and Wooster (2015) provided evidence that shares on Facebook could be marginally helpful to projects.

Crosetto and Regner (2014) based their study on the biggest crowdfunding platform in Germany-Startnext - to investigate the dynamics of funding and determinants of success. Their research focused on project types. Like in our paper, funding duration, target amount, and word count were included. They also focused on video count, image count, and blog entries, like in Xu et al. (2014), and found that the uses of patterns are highly related to the success of campaigns, and projects updates are also a significant factor in predicting success. However, initiator characteristics were not controlled for in their research. They also tracked the momentum of projects and found that eventual success can be predicted during the relative early time of a crowdfunding campaign.

Cordova et al. (2015) focused on the technology projects on four distinct crowdfunding platforms to find out what determinates the success of campaigns. They found that a higher funding goal and a longer duration are related to a lower success rate. Additionally, the dollar amount contributed per day also increases the probability of success. They also investigated how these factors affect the successful projects' overfunding rate. Beier and Wagner (2015) analyzed the success of tourism projects by crowdfunding in Switzerland. Their results show that the number of project initiators increases the chance of funding success. This means that if initiators are a group or a team, then this could be helpful for their campaign. They also reported that the use of photos and videos in the project presentation on online platforms generally does not affect the result. However, as an exception, Twitter significantly affects tourism projects. Hörisch (2015) studied whether the categories (environmental orientation) of crowdfunding projects influence outcomes. His analysis confirmed that the categories that create a tangible product, like books or videos, combined with an officially recognized non-profit title are more likely to succeed. However, he did not find a positive relationship between environmental orientation and the likelihood of a project's success. Zhou et al. (2016) considered the crowdfunding process as a persuasion reaction through projects' descriptions. They identified five exemplary antecedents-length, readability, tone, past experience, and past expertise-from project descriptions, and investigated their impacts on funding success. The results show that these antecedents are significantly correlated with success. They also looked into the effect of timeliness and found that old data on projects are becoming less and less relevant and lose predictive power about newly created projects.

Time is also an important factor that can affect the results of funding. When money is to be invested and how much money has already been collected can significantly affect projects' probability of success. Kuppuswamy and Bayus (2018) reported a high correlation of the success rate with the timeline. During the first and last weeks of a campaign, supporters are more likely to pledge and the deadline effect is strong. This pattern is also consistent with that of support from family members, which tends to be provided at the beginning and at the end of projects.

Money that already has been pledged also affects potential backers. Donations are positively correlated with updates, which are also mostly posted during the first and last weeks of the funding 
cycle. Robertson and Wooster (2015) focused on the characteristics of the first day of a campaign and found that the more money raised on the first day, the more successful the campaign is in the end. However, a contradiction appears when total backers are controlled for: the more people who back the campaign on the first day, the less successful the campaign is in the end. Li et al. (2016) concluded that temporal features, which are obtained during the first three days of the process, can dramatically improve performance predictions. They used a censored regression model, which incorporates both successful and failed projects for prediction. It is indicated that, compared with a model that only uses successful projects, a model that includes both failed and successful projects provides better predictive power.

Some empirical studies have investigated the role geography plays in determining success in crowdfunding campaigns. Agrawal et al. (2011) thoroughly investigated the relationship between geographic distance and willingness to invest. Their results indicate that online crowdfunding provides advantages to small and early-stage projects, and this finding contrasts with empirical theories that early ventures and investors are sensitive to geography and distance (Mason 2007; Guenther et al. 2018). The geographic dispersion of investment is beneficial to traditional ventures with distance-related economic frictions. In fact, the online platform provides early-stage entrepreneurs with an environment in which they can show their ideas and proposals. However, their research implies that distance plays a role in financing, and the average distance between initiators and investors over the internet is about $5000 \mathrm{~km}$. Mollick (2014) also reported that the geographic factor also plays a vital role in crowdfunding outcomes, because projects proposed by founders could reflect the underlying cultural products of that location.

The theoretical framework used by most of the studies in crowdfunding studies is signaling theory ${ }^{1}$. When two parties are operating in an environment with information asymmetry, the more informed party has to convey its quality to the less informed party through credible signals otherwise the market will collapse (Connelly et al. 2011). In case of crowdfunding, the initiators have more information about their intentions, products, and services. The investors have to make a decision about investing in the ideas and products of the initiators based on the quality of the signals provided by those initiators. Our first hypothesis is based on the fact that groups, teams, and organizations convey more credibility than individuals in this context. Teams and groups indicate that the required expertise for the successful completion of a project already exists among the initiators.

Compared with individual initiators, a team or a company of initiators seems more formal, leading members who are unknown to one another to gain trust in each other."

Hypothesis 1 (H1). Teams and companies could increase their odds of success compared with individuals simply by being in a group.

The title of the campaign creates the first impression in the minds of the investors. Crowdfunders with a limited attention span (Vachelard et al. 2016) and a poor description of the project in their title may lead to an instant rejection of their project. Indicating a specific product in the title could help investors to recognize projects more quickly and clearly in some cases they do not have the patience to read all of the details about a project.

Hypothesis 2 (H2). Indicating a specific product in the project's title enhances funding outcomes.

Greenberg and Mollick (2015) studied the gender homophily effects in crowdfunding, meaning women's willingness to support other women, and concluded that female founders receive less funding capital because a smaller proportion of women are involved in decision-making. Gorbatai and Nelson (2015) proposed that women's success rate is systematically higher than men's, because

1 We are thankful to an anonymous referee for suggesting this. 
of the different linguistic style and language used by women and by men. They use a sample of Technology and Small Business categories on the crowdfunding platform-Indiegogo-to verify their conjecture: "the institution of crowdfunding may reduce gender inequalities in the fundraising arena by benefitting the communication style of women" (Gorbatai and Nelson 2015, p. 1). They mainly focused on the impact of holistic qualities of the text, such as lexical diversity, a measure of writing and speech proficiency, readability, and concreteness. Their paper analyzes how the communication style of initiators influences campaign outcomes. However, they do not control for many basic characteristics. The inclusion of these variables in our study makes it more comprehensive. We also investigated the role anonymity plays in the success of different campaigns.

A number of other studies have also investigated the role of gender in economic and corporate decisions. In the context of crowdfunding, gender may also signal the trustworthiness of the initiators. Because females are considered to be more trustworthy than are males (Chaudhuri et al. 2013) and women as a group are considered to be more benevolent, have more integrity, and have more cultural similarities (Golesorkhi 2006), funding results should be positively related to females.

Hypothesis 3 (H3). Female initiators have higher odds of success in crowdfunding and can raise more money than can male initiators.

According to $\mathrm{Ba}$ (2001, p. 323), initiators with real names could obtain more trust online while some nicknames will raise the concern that "on the Internet, no one knows you are a dog," which increases risks and uncertainties. We expect that anonymous initiators have lower odds of success and raise less money compared to the initiators that use their real names. On the other hand, an online platform provides the opportunity for strangers to donate their money to interesting and prospective projects, meaning who creates the projects does not really matter as long as the project itself is appealing. However, researchers have investigated the evolutionary roots of strong reciprocity. Strong reciprocity has been defined as the demonstration of prosocial and cooperative behavior by individuals, even when they know there will be no reciprocity (Price 2008). Gintis et al. (2008) asserted that this behavior has led to the survival of more altruistic groups and has evolutionary advantages. Even though Price (2008) and Gintis et al. (2008) disagreed about the origin and adaptation of altruism towards strangers, they admitted that people behave ethically, even when they are acting anonymously ${ }^{2}$.

Hypothesis 4a (H4a). Real name initiators have higher odds of success in crowdfunding and can raise more money.

Hypothesis $4 \mathbf{b}(\mathbf{H} 4 \mathbf{b})$. Anonymous initiators have higher odds of success in crowdfunding and can raise more money.

However, in the existing research, only a few studies include non-profit-oriented crowdfunding projects. Belleflamme et al. (2013) pointed out that non-profit organizations may be more successful in using crowdfunding, which is in line with contract failure theory. The contract failure theory gives a reason for the existence of non-profit organizations and states that non-profits can raise more funds, because they pay more attention to the protection of consumers and the social outcomes rather than to increased monetary gains. Read (2013) showed that non-profit status can benefit projects and can attract higher potential funding. Some physical rewards, such as "thank you" letters, unlike returns for profitable projects, could produce greater benefits, because these rewards are perceived as a signal of trustworthiness. The action of donating could increase supporters' feelings of obtaining social benefits

2 Price (2008) considered it to be an evolutionary mistake, whereas Gintis et al. (2008) considered it an advantage, as our hunter gatherer ancestors had to travel long distances in search of food and mates and encountered many strangers. Ethical and prosocial behavior had an advantage in this environment. 
and produce physical rewards that better indicate how donated money is allocated. Lambert and Schwienbacher (2010) noted that crowdfunding initiatives structured as non-profit organizations tend to be significantly more successful than other crowdfunding platforms. Carvajal et al. (2012) provided an insight into the nature of crowdfunding and its impact on non-profit media. They investigated the growing impact of crowdfunding on journalism by providing an explanation of the context where it is taking place. The study of Song et al. (2015) is based on Korean largest non-profit crowdfunding platform, HAPPYNEAN. They analyzed donor behavior on this platform. They found that donations of small amounts of money and only a few times by the same donors greatly affect the success of projects. McGowan indicated that the trust between non-profit organizations and crowdfunding platforms, between donors and crowdfunding platforms, and between donors and non-profit organizations need to be developed. Our study focuses on the success of these organization relative to others.

According to contract failure theory and to former research on the effect of non-profit organizations in crowdfunding, we expect that organizations with non-profit orientations, such as some institutes or schools, are more successful in online crowdfunding.

Hypothesis 5 (H5). Non-profit organizations have higher odds of success in crowdfunding and can raise more money.

\section{Data Summary}

This research used a dataset, from 1 January 2015 to 30 June 2015, from Kickstarter, one of the largest and most popular online crowdfunding websites, containing 27,117 cases. In all the projects during this period, the total amount of raised targets is $\$ 1,845,572,724$, and the total pledged amount is $\$ 293,338,289$. The threshold pledge model was applied (Crosetto and Regner 2014), also known as the "All-or-Nothing" model (Cumming et al. 2015), and only projects for which the goal is reached were classified as successful campaigns. Failed, suspended, and canceled projects were classified as failures. In 27,117 projects, 8832 cases were successfully funded (32.57\%) and 18,285 cases failed $(67.43 \%)$.

The projects in this dataset cover 15 industries, including art, comics, crafts, dance, design, fashion, film and video, food, games, journalism, music, photography, publishing, technology, and theater, which were originally set by Kickstarter. From the descriptive data of individual projects (Table 1), one can find some similarities and differences in characteristics among these industries. Film and video, food, games, music, publishing, and technology are all highly prevalent domains nowadays, and many people come up with creative ideas in these areas and hope to start their own businesses. Table 1 shows that the majority of funds seekers in online platforms are male, and the number of male founders is significantly higher than that of female founders in all industries except for dance. In the most popular industries, the number of projects created by males is more than 3 times the number initiated by females. Especially in the games and technology fields, the number of projects initiated by women is only about one-tenth of those initiated by men. The average success rate is around $30 \%$. Except for in the crafts and design industries, women are more successful in raising funds than are men in all industries. This is in contrast with the number of projects created. In the comics, film and video, and music industries, the mean difference of the success rate between males and females is huge, at more than $15 \%$. This means in these industries, people can take advantage of gender diversity to increase their probability of success of obtaining funding. The complete analysis of the gender effect will be shown in a later part of the paper. Another point worth noticing is that in the comics industry, the probability of success exceeds $50 \%$ and in dance, film and video, music, and theater industries, around half of all the projects are successful in eventually getting funded. This provides us with a guide to the trend in different industries that most appeals to the public. Table 2 also indicates that men can more easily create a campaign and are more likely to do so (men are responsible for more than twice the number of women's campaigns) but women are systematically more successful than men, which may be contrary to offline gender inequality (Gorbatai and Nelson 2015). 
Table 1. Individual projects by gender. This table provides the success rate of projects by gender in different industries.

\begin{tabular}{|c|c|c|c|c|}
\hline Industry & Male & Obs & Mean & SD \\
\hline \multirow[t]{2}{*}{ Art } & 0 & 599 & 0.3990 & 0.4901 \\
\hline & 1 & 958 & 0.2985 & 0.4579 \\
\hline \multirow[t]{2}{*}{ Comics } & 0 & 291 & 0.6813 & 0.4685 \\
\hline & 1 & 480 & 0.5083 & 0.5005 \\
\hline \multirow{2}{*}{ Crafts } & 0 & 488 & 0.1864 & 0.3899 \\
\hline & 1 & 480 & 0.1917 & 0.3940 \\
\hline \multirow[t]{2}{*}{ Dance } & 0 & 136 & 0.4118 & 0.4940 \\
\hline & 1 & 59 & 0.3729 & 0.4877 \\
\hline \multirow[t]{2}{*}{ Design } & 0 & 244 & 0.3689 & 0.4835 \\
\hline & 1 & 721 & 0.3856 & 0.4871 \\
\hline \multirow[t]{2}{*}{ Fashion } & 0 & 549 & 0.2095 & 0.4073 \\
\hline & 1 & 865 & 0.1480 & 0.3553 \\
\hline \multirow[t]{2}{*}{ Film and video } & 0 & 577 & 0.5009 & 0.5004 \\
\hline & 1 & 1989 & 0.3157 & 0.4649 \\
\hline \multirow[t]{2}{*}{ Food } & 0 & 652 & 0.2101 & 0.4077 \\
\hline & 1 & 1125 & 0.1636 & 0.3700 \\
\hline \multirow[t]{2}{*}{ Games } & 0 & 137 & 0.3650 & 0.4832 \\
\hline & 1 & 1071 & 0.3613 & 0.4806 \\
\hline \multirow[t]{2}{*}{ Journalism } & 0 & 156 & 0.1474 & 0.3557 \\
\hline & 1 & 387 & 0.1214 & 0.3271 \\
\hline \multirow[t]{2}{*}{ Music } & 0 & 587 & 0.5128 & 0.5003 \\
\hline & 1 & 1728 & 0.3559 & 0.4789 \\
\hline \multirow[t]{2}{*}{ Photography } & 0 & 225 & 0.2444 & 0.4307 \\
\hline & 1 & 491 & 0.2200 & 0.4146 \\
\hline \multirow[t]{2}{*}{ Publishing } & 0 & 769 & 0.3121 & 0.4636 \\
\hline & 1 & 1345 & 0.2684 & 0.4432 \\
\hline \multirow{2}{*}{ Technology } & 0 & 296 & 0.1622 & 0.3692 \\
\hline & 1 & 1927 & 0.0986 & 0.2982 \\
\hline \multirow[t]{2}{*}{ Theater } & 0 & 173 & 0.5376 & 0.5000 \\
\hline & 1 & 215 & 0.4651 & 0.4999 \\
\hline
\end{tabular}

Table 2. Comparison of Success Rate between Genders.

\begin{tabular}{ccccccccc}
\hline Male & Obs & Method & Mean & $\mathbf{9 5 \% ~ C I ~}$ & Mean & SD & 95\% CI & SD \\
\hline 0 & 5679 & & 0.3326 & 0.3204 & 0.3449 & 0.4712 & 0.4627 & 0.4800 \\
1 & 13,841 & & 0.2652 & 0.2578 & 0.2725 & 0.4414 & 0.4363 & 0.4467 \\
Diff (1-2) & & Pooled & 0.0675 & 0.0536 & 0.0814 & 0.4503 & 0.4459 & 0.4548 \\
Diff (1-2) & & Satterthwaite & 0.0675 & 0.0532 & 0.0818 & & & \\
\hline
\end{tabular}

Key variables in the data were considered, including the explanatory characteristics of the project itself, the types and traits of founders, and geographic features. The projects' characteristics consist of the fund target, the amount of money raised, the margin amount (to eliminate the outliers' effect, the logarithm form is used), the number of words in the project descriptions, the number of backers who support the project, the number of comments on the project, the number of projects created by the same initiator, the updates made by initiators, and project duration. Across the types and traits of founders, we created several dummies, including gender, team, project, company, and non-profit. The city population of the place in which the project originated was also included. We also investigated whether or not the geographical location is inside the United States. Table 3 summarizes the definitions and features of these variables. Table 4 provides descriptive statistics of different variables used in this study. 
Table 3. Descriptions of variables. This table provides descriptions of the different variables used in this study.

\begin{tabular}{|c|c|}
\hline Variable Name & Descriptions \\
\hline Result & $\begin{array}{l}\text { Dummy equal to } 1 \text { if the money raised by the entrepreneur exceeds the target amount, which } \\
\text { means achieving success in crowdfunding }\end{array}$ \\
\hline Total failure & Dummy variable equal to one when no amount is raised and zero otherwise \\
\hline More than aim & Dummy variable equal ti one when the amount raised is greater than aim and zero otherwise \\
\hline Laim & $\begin{array}{l}\text { Logarithmic form of total funds set initially (in USD) from the crowdfunding project by the } \\
\text { entrepreneur }\end{array}$ \\
\hline Lamount & $\begin{array}{l}\text { Logarithmic form of total funds eventually raised (in USD) by the entrepreneur between the } \\
\text { start date from } 1 \text { January } 2015 \text {, until the end date }\end{array}$ \\
\hline Marginp & Equal to the logarithmic form of funds raised minus funds target \\
\hline Words & The number of words in the description of each campaign \\
\hline Backers & The number of backers that support the crowdfunding campaign \\
\hline Comments & The number of comments that each campaign has on the home page \\
\hline Nprojects & The number of projects that the initiator created in Kickstarter until 30 June 2015 \\
\hline updates & The pieces of updates that initiator adds on the project's homepage \\
\hline Lpop & $\begin{array}{l}\text { Logarithmic form of the local population of the city where the project originates. These data } \\
\text { are based on the city level by the U.S. Census }\end{array}$ \\
\hline Duration & The time length of the project \\
\hline Gender & Dummy equal to 1 if the initiator is a man and 0 if they are a woman \\
\hline Team & Dummy equal to 1 if the initiator is a team or a group and 0 if not \\
\hline Project & Dummy equal to 1 if the name of initiator is a specific project and 0 if not \\
\hline Company & Dummy equal to 1 if the crowdfunding initiative is structured as a company and 0 if not \\
\hline Non-profit & $\begin{array}{l}\text { Dummy equal to } 1 \text { if the crowdfunding initiative is on behalf of a not-for-profit organization } \\
\text { or institution and } 0 \text { if not }\end{array}$ \\
\hline U.S. & $\begin{array}{l}\text { Dummy equal to } 1 \text { if the crowdfunding campaign originates inside the United States and } 0 \text { if } \\
\text { it originates from other countries }\end{array}$ \\
\hline
\end{tabular}

Table 4. Descriptive data of variables. This table provides the descriptive statistics of the different variables used in this study. Table 3 defines all the variables.

\begin{tabular}{cccccc}
\hline Variable & Mean & Median & Minimum & Maximum & SD \\
\hline Result & 0.3257 & 0 & 0 & 1 & 0.4687 \\
Word & 19.3510 & 20 & 1 & 61 & 5.1779 \\
Aim & $68,064.64$ & 6000 & 1 & $100,000,000$ & $1,601,207.3$ \\
Amount & $10,818.3$ & 271 & 0 & $20,338,986$ & $158,530.9$ \\
Marginp & 2.5753 & 0.0594 & 0 & 12,984 & 101.5547 \\
Duration & 33.8780 & 30 & 1 & 73 & 11.8052 \\
Backers & 119.5221 & 6 & 0 & 219,382 & 1661.47 \\
Comments & 41.7002 & 0 & 0 & 113,219 & 1163.73 \\
Nprojects & 5.2152 & 0 & 0 & 174 & 9.6965 \\
Updates & 4.0057 & 1 & 0 & 140 & 7.5261 \\
Male & 0.5105 & 1 & 0 & 1 & 0.5000 \\
Female & 0.2094 & 0 & 0 & 1 & 0.4069 \\
Company & 0.0677 & 0 & 0 & 1 & 0.2513 \\
Non-profit & 0.0038 & 0 & 0 & 1 & 0.0615 \\
Team & 0.0556 & 0 & 0 & 1 & 0.2291 \\
Projects & 0.0124 & 0 & 0 & 1 & 0.1108 \\
U.S. & 0.9651 & 1 & 0 & 1 & 0.1834 \\
\hline
\end{tabular}

\section{Methodology}

We used a well-established methodology to investigate all these questions. We examined factors that influence the funding outcomes by using univariate analysis, logistical regression analysis, and linear regression analysis. Industry effects were controlled in all these tests.

In univariate analysis, we mainly compared the means and medians of variables. This descriptive method can demonstrate a direct and a brief feature of how different variables are distributed. 
In the second step, the determinants of the probability of a project's success were investigated. Dummy variables were created to estimate the logistical regression model. For this step, we used a separate dataset for individuals and companies to figure out whether the project categories affected our results.

For the whole dataset, the initiator categories were investigated. We divided all initiators into four categories: individuals, companies, teams, and projects. Our model is illustrated in Equation (1):

$$
P(\text { Success }=1)=\beta_{1} \text { Dindividual }+\beta_{2} \text { Dcompany }+\beta_{3} \text { Dteam }+\beta_{4} \text { Dteam }+\beta_{i} X_{i}+\epsilon_{i}
$$

where $X_{i}$ are control variables, including the number of words, updates, log amount, backers, comments, project numbers, and $\log$ city population, while $\varepsilon_{i}$ is standard errors. This model shows perspicuous results of how the investors' first impression from the initiators' name influences the outcome of funding.

For the sub-dataset that includes only individuals, we try to identify whether males or females and real names or anonymity will affect funding outcomes. The following two logistical regression models were created to estimate projects' likelihood of being funded:

$$
\begin{gathered}
P(\text { Success }=1)=\beta_{1} \text { Dfemale }+\beta_{i} X_{i}+\epsilon_{i} \\
P(\text { Success }=1)=\beta_{1} \text { Danonymous }+\beta_{i} X_{i}+\epsilon_{i}
\end{gathered}
$$

where $X_{i}$ are control variables including the number of words, updates, log amount, backers, pieces of comments, projects number, and log city population, while $\varepsilon_{i}$ is standard errors. Dfemale is the dummy variable that equals 1 if the initiator is a female and 0 otherwise, and Danonymous is the dummy that equals 1 if the initiator is anonymous and 0 otherwise.

For the separate company dataset, we split it into to two parts: profitable companies and non-profit organizations. Organizations like charitable associations, schools, centers, and committees were considered to be non-profits:

$$
P(\text { Success }=1)=\beta_{1} \text { Dorganization }+\beta_{i} X_{i}+\epsilon_{i}
$$

where $X_{i}$ and $\varepsilon_{i}$ are same as the former equations and Dorganization equals 1 if the initiator is a non-profit organization and 0 otherwise.

In ordinary least squares (OLS) regression analysis, we tried to discover the quantitative relationship between variables and the actual money raised and the duration. The variables that affect the margin percentage of money funded to the target and the actual money funded were analyzed with the following models:

$$
\begin{gathered}
Y(\log \text { amount })=\beta_{i} X_{i}+\epsilon_{i} \\
Y(\text { Duration })=\beta_{i} X_{i}+\epsilon_{i} \\
Y(\text { margin percentage } \text { funded })=\beta_{i} X_{i}+\epsilon_{i}
\end{gathered}
$$

\section{Empirical Results}

\subsection{Univariate Analysis}

Table 5 reports summary statistics of two groups: successful projects and failed projects. The differences of means and medians between successful and failed crowdfunding are significantly different from 0 , except for with the female category.

For campaigns' characteristics, no important differences in the number of description words and the length of time projects can be found between the two groups. It seems that the fund target matters a lot. Based on Table 5, successful projects tend to have more realistic goals compared with failing projects. The mean aim of failed projects is $\$ 95,333$, which means that initiators have to collect almost $\$ 100,000$ from other people, but successful projects just request, on average, $\$ 11,616.1$ for each project. 
An inflated target can scare investors away, and this finding is also consistent with the result of later regression analysis. In this case, actual funds raised in the end by successful projects $(\$ 30,993)$ are substantially higher than those raised by failed projects (\$1072.5). An almost 30-time gap in funds raised and a 10-time gap in targets implies a tremendous margin that means that projects with a lower target are much more likely to be fully funded. We also further investigate some extreme observations, with the margin of millions and percentage of more than $5000 \%$. We find that these campaigns mostly have tiny targets, such as $\$ 1$ or less than $\$ 100$. Consequently, the mean percentage of the amount funded to its goal is also largely distinguished: $7.5 \%$ for failed projects and $775 \%$ for successful projects, which means projects that fail tend to fail by large margins and projects that succeed also tend to succeed by large margins. In addition, the number of updates of successful projects is 10 times that of failed ones. More updates provide more information to investors and show the feasibility of the project, which could be a indication of high quality. Furthermore, comparing failed projects and successful projects, the gap between backers and pieces of comments of the two groups is substantially large: on average for each project, 12 backers and one comment for failed projects but 342 backers and 126 comments for successful ones.

Table 5. Univariate analysis. This table provides the univariate analysis of the mean and the median difference between variables used in this study. Table 3 defines all the variables.

\begin{tabular}{cccccccc}
\hline \multirow{2}{*}{ Variables } & \multicolumn{2}{c}{ Mean } & \multirow{2}{*}{$\boldsymbol{t}$-Value } & $\boldsymbol{p}$-Value & \multicolumn{2}{c}{ Median } & \multirow{2}{*}{$\boldsymbol{p}$-Value } \\
\cline { 2 - 3 } \cline { 6 - 7 } & Success & Failure & & & Success & Failure & \\
\hline Word & 19.274 & 19.39 & 1.77 & 0.077 & 20 & 20 & $<0.001$ \\
Aim & $11,616.1$ & $95,333.3$ & 5.81 & 0.001 & 5000 & 7500 & $<0.001$ \\
Amount & 30,993 & 1072.5 & -10.17 & 0.001 & 5988 & 30 & $<0.001$ \\
Percentage & 6.751 & 0.925 & -4.06 & 0.001 & 0.17 & 0.996 & $<0.001$ \\
Duration & 31.109 & 35.217 & 29.66 & 0.001 & 30 & 30 & $<0.001$ \\
Backers & 341.5 & 12.118 & -10.68 & 0.001 & 75 & 2 & $<0.001$ \\
Comments & 125.6 & 1.17 & -5.74 & 0.001 & 3 & 0 & $<0.001$ \\
Nprojects & 9.137 & 3.321 & -41.22 & 0.001 & 5 & 0 & $<0.001$ \\
Updates & 10.029 & 1.089 & -81.387 & 0.001 & 7 & 0 & $<0.001$ \\
Male & 0.415 & 0.556 & 22 & 0.001 & 0 & 1 & $<0.001$ \\
Female & 0.214 & 0.207 & -1.24 & 0.214 & 0 & 0 & 0.212 \\
Company & 0.095 & 0.055 & -11.4 & 0.001 & 0 & 0 & $<0.001$ \\
Org & 0.0063 & 0.0026 & -4.08 & 0.001 & 0 & 0 & $<0.001$ \\
Team & 0.076 & 0.046 & -9.36 & 0.001 & 0 & 0 & $<0.001$ \\
Project & 0.023 & 0.007 & -9.51 & 0.001 & 0 & 0 & $<0.001$ \\
U.S. & 0.957 & 0.969 & 5.08 & 0.001 & 1 & 1 & $<0.001$ \\
\hline
\end{tabular}

Comparing fundraising results among different types of initiators, some direct characteristics can be summarized. According to Table 5, for individual initiators, there are no big differences between the probability of success and failure for women, whereas men are more likely to fail than to succeed when they are trying to raise a fund. Compared with projects founded by individual initiators, projects raised by companies, or by organizations are more likely to be funded successfully. This phenomenon is also consistent with those developed by teams and those for which the campaign name is a specific project.

As can be seen from Table 5, the higher success probability of females' projects leads to our research on the gender effect in a later part of this paper. Projects' funding outcomes by different types of initiators are also investigated later.

\subsection{Regression and Logistical Analysis for the Whole Sample}

We report a correlation matrix in Table 6. Table 7 exhibits ordinary least squares (OLS) regressions and logistic regressions of the general characteristics of crowdfunding projects. As the high correlation between number of backers and number of comments, we only used backers in regressions. Table 7 provides the results of all independent variables. 
Table 6. Correlation matrix. This table reports the correlation coefficient and its significance level for each variable used in this study. Table 3 defines all the variables.

\begin{tabular}{|c|c|c|c|c|c|c|c|c|c|c|c|c|c|c|c|c|}
\hline Variable & Word & Aim & Dresult & Amount & Mpercentage & Duration & Backer & Comment & Update & Nproject & Male & Female & Company & Org & Team & Project \\
\hline Aim & $\begin{array}{l}-0.000 \\
(0.974) \\
\end{array}$ & & & & & & & & & & & & & & & \\
\hline Dresult & $\begin{array}{l}-0.011 \\
(0.083)\end{array}$ & $\begin{array}{c}-0.025 \\
(<0.0001)\end{array}$ & & & & & & & & & & & & & & \\
\hline Amount & $\begin{array}{l}-0.002 \\
(0.714)\end{array}$ & $\begin{array}{c}0.004 \\
(0.537)\end{array}$ & $\begin{array}{c}0.088 \\
(<0.0001)\end{array}$ & & & & & & & & & & & & & \\
\hline Mpercentage & $\begin{array}{l}-0.007 \\
(0.271)\end{array}$ & $\begin{array}{l}-0.001 \\
(0.868)\end{array}$ & $\begin{array}{c}0.035 \\
(<0.0001)\end{array}$ & $\begin{array}{c}0.025 \\
(<0.0001)\end{array}$ & & & & & & & & & & & & \\
\hline Duration & $\begin{array}{c}0.018 \\
(0.004)\end{array}$ & $\begin{array}{c}0.036 \\
(<0.0001)\end{array}$ & $\begin{array}{c}-0.163 \\
(<0.0001)\end{array}$ & $\begin{array}{l}-0.001 \\
(0.812)\end{array}$ & $\begin{array}{l}-0.021 \\
(0.001)\end{array}$ & & & & & & & & & & & \\
\hline Backer & $\begin{array}{l}-0.007 \\
(0.253)\end{array}$ & $\begin{array}{c}0.003 \\
(0.658)\end{array}$ & $\begin{array}{c}0.093 \\
(<0.0001)\end{array}$ & $\begin{array}{c}0.731 \\
(<0.0001)\end{array}$ & $\begin{array}{c}0.049 \\
(<0.0001)\end{array}$ & $\begin{array}{l}-0.005 \\
(0.396)\end{array}$ & & & & & & & & & & \\
\hline Comment & $\begin{array}{l}-0.006 \\
(0.334)\end{array}$ & $\begin{array}{c}0.005 \\
(0.372)\end{array}$ & $\begin{array}{c}0.050 \\
(<0.0001)\end{array}$ & $\begin{array}{c}0.633 \\
(<0.0001)\end{array}$ & $\begin{array}{c}0.030 \\
(<0.0001)\end{array}$ & $\begin{array}{l}-0.010 \\
(0.103)\end{array}$ & $\begin{array}{c}0.727 \\
(<0.0001)\end{array}$ & & & & & & & & & \\
\hline Update & $\begin{array}{l}-0.011 \\
(0.072)\end{array}$ & $\begin{array}{l}-0.013 \\
(0.035)\end{array}$ & $\begin{array}{c}0.557 \\
(<0.0001)\end{array}$ & $\begin{array}{c}0.172 \\
(<0.0001)\end{array}$ & $\begin{array}{c}0.050 \\
(<0.0001)\end{array}$ & $\begin{array}{c}-0.059 \\
(<0.0001)\end{array}$ & $\begin{array}{c}0.173 \\
(<0.0001)\end{array}$ & $\begin{array}{c}0.172 \\
(<0.0001)\end{array}$ & & & & & & & & \\
\hline Nproject & $\begin{array}{l}-0.043 \\
(<0.0001)\end{array}$ & $\begin{array}{l}-0.011 \\
(0.076)\end{array}$ & $\begin{array}{c}0.281 \\
(<0.0001)\end{array}$ & $\begin{array}{c}0.159 \\
(<0.0001)\end{array}$ & $\begin{array}{c}0.032 \\
(<0.0001)\end{array}$ & $\begin{array}{l}-0.014 \\
(0.017)\end{array}$ & $\begin{array}{c}0.149 \\
(<0.0001)\end{array}$ & $\begin{array}{c}0.136 \\
(<0.0001)\end{array}$ & $\begin{array}{c}0.480 \\
(<0.0001)\end{array}$ & & & & & & & \\
\hline Male & $\begin{array}{c}0.008 \\
(0.187)\end{array}$ & $\begin{array}{c}0.016 \\
(0.007)\end{array}$ & $\begin{array}{c}-0.132 \\
(<0.0001)\end{array}$ & $\begin{array}{c}-0.031 \\
(<0.0001)\end{array}$ & $\begin{array}{l}-0.016 \\
(0.010)\end{array}$ & $\begin{array}{c}0.011 \\
(0.063)\end{array}$ & $\begin{array}{c}-0.026 \\
(<0.0001)\end{array}$ & $\begin{array}{l}-0.016 \\
(0.009)\end{array}$ & $\begin{array}{c}-0.090 \\
(<0.0001)\end{array}$ & $\begin{array}{c}-0.116 \\
(<0.0001)\end{array}$ & & & & & & \\
\hline Female & $\begin{array}{c}0.010 \\
(0.087)\end{array}$ & $\begin{array}{l}-0.009 \\
(0.153)\end{array}$ & $\begin{array}{c}0.008 \\
(0.212)\end{array}$ & $\begin{array}{l}-0.017 \\
(0.004)\end{array}$ & $\begin{array}{l}-0.010 \\
(0.131)\end{array}$ & $\begin{array}{c}-0.024 \\
(<0.0001)\end{array}$ & $\begin{array}{l}-0.010 \\
(0.098)\end{array}$ & $\begin{array}{l}-0.001 \\
(0.123)\end{array}$ & $\begin{array}{c}-0.045 \\
(<0.0001)\end{array}$ & $\begin{array}{c}-0.086 \\
(<0.0001)\end{array}$ & $\begin{array}{c}-0.526 \\
(<0.0001)\end{array}$ & & & & & \\
\hline Company & $\begin{array}{l}-0.017 \\
(0.006)\end{array}$ & $\begin{array}{l}-0.005 \\
(0.434)\end{array}$ & $\begin{array}{c}0.075 \\
(<0.0001)\end{array}$ & $\begin{array}{c}0.054 \\
(<0.0001)\end{array}$ & $\begin{array}{l}-0.001 \\
(0.872)\end{array}$ & $\begin{array}{c}0.015 \\
(0.014)\end{array}$ & $\begin{array}{c}0.043 \\
(<0.0001)\end{array}$ & $\begin{array}{c}0.024 \\
(<0.0001)\end{array}$ & $\begin{array}{c}0.112 \\
(<0.0001)\end{array}$ & $\begin{array}{c}0.165 \\
(<0.0001)\end{array}$ & $\begin{array}{c}-0.275 \\
(<0.0001)\end{array}$ & $\begin{array}{c}-0.139 \\
(<0.0001)\end{array}$ & & & & \\
\hline Org & $\begin{array}{l}-0.002 \\
(0.699)\end{array}$ & $\begin{array}{l}-0.001 \\
(0.850)\end{array}$ & $\begin{array}{c}0.029 \\
(<0.0001)\end{array}$ & $\begin{array}{l}-0.001 \\
(0.831)\end{array}$ & $\begin{array}{l}-0.001 \\
(0.854)\end{array}$ & $\begin{array}{c}0.011 \\
(0.068)\end{array}$ & $\begin{array}{l}-0.001 \\
(0.816)\end{array}$ & $\begin{array}{l}-0.002 \\
(0.735)\end{array}$ & $\begin{array}{l}-0.004 \\
(0.536)\end{array}$ & $\begin{array}{l}-0.003 \\
(0.668)\end{array}$ & $\begin{array}{c}-0.063 \\
(<0.0001)\end{array}$ & $\begin{array}{c}-0.031 \\
(<0.0001)\end{array}$ & $\begin{array}{c}0.229 \\
(<0.0001)\end{array}$ & & & \\
\hline Team & $\begin{array}{c}0.006 \\
(0.292)\end{array}$ & $\begin{array}{l}-0.007 \\
(0.275)\end{array}$ & $\begin{array}{c}0.062 \\
(<0.0001)\end{array}$ & $\begin{array}{c}0.003 \\
(0.673)\end{array}$ & $\begin{array}{c}0.010 \\
(0.093)\end{array}$ & $\begin{array}{l}-0.001 \\
(0.888)\end{array}$ & $\begin{array}{c}0.002 \\
(0.759)\end{array}$ & $\begin{array}{l}-0.006 \\
(0.334)\end{array}$ & $\begin{array}{c}0.024 \\
(<0.0001)\end{array}$ & $\begin{array}{c}0.028 \\
(<0.0001)\end{array}$ & $\begin{array}{c}-0.248 \\
(<0.0001)\end{array}$ & $\begin{array}{c}-0.125 \\
(<0.0001)\end{array}$ & $\begin{array}{c}-0.065 \\
(<0.0001)\end{array}$ & $\begin{array}{l}-0.015 \\
(0.014)\end{array}$ & & \\
\hline Project & $\begin{array}{l}-0.002 \\
(0.742)\end{array}$ & $\begin{array}{l}-0.003 \\
(0.594)\end{array}$ & $\begin{array}{c}0.069 \\
(<0.0001)\end{array}$ & $\begin{array}{c}0.013 \\
(0.102)\end{array}$ & $\begin{array}{c}0.025 \\
(<0.0001)\end{array}$ & $\begin{array}{c}-0.025 \\
(<0.0001)\end{array}$ & $\begin{array}{c}0.028 \\
(<0.0001)\end{array}$ & $\begin{array}{c}0.026 \\
(<0.0001)\end{array}$ & $\begin{array}{c}0.127 \\
(<0.0001)\end{array}$ & $\begin{array}{c}0.132 \\
(<0.0001)\end{array}$ & $\begin{array}{c}-0.115 \\
(<0.0001)\end{array}$ & $\begin{array}{c}-0.058 \\
(<0.0001)\end{array}$ & $\begin{array}{c}-0.030 \\
(<0.0001)\end{array}$ & $\begin{array}{l}-0.007 \\
(0.253)\end{array}$ & $\begin{array}{c}-0.027 \\
(<0.0001)\end{array}$ & \\
\hline U.S. & $\begin{array}{c}0.015 \\
(0.013)\end{array}$ & $\begin{array}{l}-0.000 \\
(0.991)\end{array}$ & $\begin{array}{c}-0.033 \\
(<0.0001)\end{array}$ & $\begin{array}{c}-0.028 \\
(<0.0001)\end{array}$ & $\begin{array}{c}0.002 \\
(0.711)\end{array}$ & $\begin{array}{l}-0.012 \\
(0.051)\end{array}$ & $\begin{array}{c}-0.026 \\
(<0.0001)\end{array}$ & $\begin{array}{c}-0.034 \\
(<0.0001)\end{array}$ & $\begin{array}{c}-0.030 \\
(<0.0001)\end{array}$ & $\begin{array}{c}-0.101 \\
(<0.0001)\end{array}$ & $\begin{array}{c}0.028 \\
(<0.0001)\end{array}$ & $\begin{array}{l}-0.006 \\
(0.287)\end{array}$ & $\begin{array}{l}-0.011 \\
(0.066)\end{array}$ & $\begin{array}{l}-0.014 \\
(0.0172)\end{array}$ & $\begin{array}{l}-0.014 \\
(0.017)\end{array}$ & $\begin{array}{c}-0.024 \\
(<0.0001)\end{array}$ \\
\hline
\end{tabular}


Table 7. Results for the whole sample. This table reports results of regression analysis of the success, amount raised, duration, and margin (\%) for the complete sample. We controlled for different variables. Table 3 defines all the variables.

\begin{tabular}{ccccc}
\hline \multirow{2}{*}{ Variable } & $\mathbf{( 1 )}$ & $\mathbf{( 2 )}$ & $\mathbf{( 3 )}$ & $\mathbf{( 4 )}$ \\
\cline { 2 - 5 } & Result & Lamount & Duration & Marginp \\
\hline Duration & $-0.025^{* * *}$ & $-0.014^{* * *}$ & & $-0.133^{* * * *}$ \\
& $(0.002)$ & $(0.002)$ & & $(0.030)$ \\
Updates & $0.414^{* * *}$ & $0.172^{* * *}$ & $-0.088^{* * *}$ & $0.155^{* * *}$ \\
& $(0.007)$ & $(0.002)$ & $(0.011)$ & $(0.053)$ \\
Laim & $-0.604^{* * *}$ & & $1.538^{* * *}$ & \\
& $(0.015)$ & & $(0.045)$ & \\
Backers & $0.045^{* * *}$ & 0.000 & -0.000 & $0.003^{* * *}$ \\
& $(0.003)$ & $(0.000)$ & $(0.000)$ & $(0.000)$ \\
NProjects & $0.000^{* * *}$ & $0.000^{* * *}$ & $-0.000^{* * *}$ & -0.000 \\
& $(0.000)$ & $(0.000)$ & $(0.000)$ & $(0.000)$ \\
U.S. & $-0.283^{* *}$ & $-0.495^{* * *}$ & $-0.772^{*}$ & 1.019 \\
& $(0.113)$ & $(0.093)$ & $(0.419)$ & $(1.939)$ \\
Word & -0.003 & $-0.009^{* * *}$ & $0.037^{* *}$ & 0.011 \\
& $(0.005)$ & $(0.003)$ & $(0.015)$ & $(0.068)$ \\
Constant & $5.020^{* * *}$ & $6.781^{* * *}$ & $19.942^{* * *}$ & 2.793 \\
& $(0.202)$ & $(0.163)$ & $(0.798)$ & $(3.402)$ \\
Industry effect & Yes & Yes & Yes & Yes \\
Observations & 23,201 & 18,489 & 23,194 & 23,194 \\
$R$-squared & & 0.365 & 0.060 & 0.006 \\
\hline Standard are errors in parentheses. ${ }^{*} p<0.1 ; * *$ & $p<0.05 ; * * *<0.01$. \\
\hline
\end{tabular}

According to Table 7, the results show that the number of words is detrimental to funding outcomes. For each one additional word in the description, the log total amount collected significantly decreases by 0.009 . However, in the project description, the total number of words does not have a significant impact on odds of success in funding. Gorbatai and Nelson (2015) studied the relationship between linguistic content and funding outcomes, including at the micro level and macro level. Zhou et al. (2016, p. 263) found that the log odds rises with increases with length as it captures "the amount of information the project owner provided." However, the length of the description affects the first impression of the project: shorter ones are perceived to be straight-forward. If the description is too long, then people may not have enough patience to finish reading it. In summary, the longer a project description is, the lower chance that project has to collect enough money.

Another factor we investigate is timing. Intuitively, the longer projects should lead to more time to raise money. We expected a positive correlation between project duration and the money raised. However, the coefficient of duration in Column (1) is negative (-0.025), which indicates the longer the duration of a project, the less chance that the project will succeed. The coefficients in Column (2) and (3) both indicate that less money will be donated to the projects with a longer funding period. We believe that behavioral procrastination could be one explanation for this finding. When donors see a long duration, they may delay their action until they possibly forget to donate. According to Solomon et al. (2015), the early donating signal will encourage later investors to donate as well, accordingly improving their chances of successfully funding a project. This indicates that a short period prompts investors to give their money more efficiently.

Another important factor that we investigate is the target amount an initiator expects to obtain. Many scholars found a negative relationship between project goals and success (Mollick 2014; Crosetto and Regner 2014; Beier and Wagner 2015; among others). The influence of a funding target is consistent with these studies (see Table 7). With an increase in the funding goal, the odds of funding success drops by $82.92 \%$ [exp (0.604)]. This means that projects with smaller funding goals are more likely to succeed in attracting donations, since investors rationally choose realistic project goals. Column (3) 
also shows that founders who set higher funding goals will usually set a longer funding period. Then in a vicious cycle, a longer duration also cuts the project's success rate.

Regarding the number of backers, we find that the more individuals support projects, the more likely that possible projects can reach their goal. Table 7 shows that the number of backers could significantly increase the odds of success and the margin percentage. With one additional backer supporting the project, the success likelihood increases by $4.6 \%$ and the margin of percentage increases by $0.3 \%$. One important point needs to be noted here is the number of backers is the total backers that support a project. However, when an individual browses a project, he or she cannot predict how many people will support the project, so this means the variable, the number of backers, does not necessarily have an impact on the odds of success. Kuppuswamy and Bayus (2018) studied this problem and found a typical U-shaped pattern of supporters: "backers are more likely to contribute to a project in the first and last week as compared to the middle period of the funding cycle," which also supports the conclusion about duration made above.

Additionally, updates are crucial to outcomes, as this behavior keeps backers informed of a project's process, which could indicate the founder's consistency and attentiveness. How many updates a project has provided indicates how actively and frequently the initiator interacts with their "audience." Xu et al. (2014) concluded that projects using specific updates have stronger associations with funding success than those with only a description. This is also consistent with our results. Projects with one more update have $51.3 \%$ increased possibility to succeed and can ultimately raise $\$ 1.19$ more. Apparently, if founders add more updates on their homepage, then their project tends to attract more funds and trust. Therefore, it has a higher likelihood of crowdfunding success.

The number of projects variable represents the number of projects created by the same initiator. From Table 7, its coefficients in all the models are significant, but the absolute value is extremely small (0.000); since we only retained three decimals, this figure can be shown to be almost zero. However, the sign of coefficients could tell some stories. The odds of success and the final raised amount are positively correlated with the number of projects created by the same founder. One possible explanation is that someone with many projects will give the public an impression that the initiator is productive and active in this field. The founder who comes up with many interesting ideas can convey more information to the public, consequently the public can recognize this person easily and will donate their money. Furthermore, the negative correlation between duration and number of projects that indicates time horizon of each project is shortened with the increase of projects created by the same initiator. They probably would like to get more preparation time for their next project if their original project failed. In conclusion, the number of projects created by the same initiator is favorable for crowdfunding.

\subsection{Logistic Analysis}

As the name of creator will be at looked at on first glance by all visitors, we try to figure out the specific relationship between their name types and their crowdfunding outcomes.

In Kickstarter, projects only can be funded in U.S. dollars, but initiators could choose their original location, which would not necessarily be in the United States. In the whole dataset, 26,170 projects out of a total of 27,115 projects come from the United States. Only 945 projects come from other regions, so we mainly analyze the U.S. sample.

\subsubsection{Whole U.S. Sample}

We divide the initiators into four groups: individuals, teams, companies, and the specific project.

From Table 8, we observe that individual status would not benefit online fund raising. The significant negative correlation $(-0.429)$ between individual and success possibility shows that with a one-unit increase in individual status, the funding success possibility will decrease by $53.6 \%$. In addition, negative coefficients of log amount $(-0.211)$ and margin percentage $(-4.138)$ both demonstrate that if a project is started by an individual, it will raise less money than expected and have 
a larger negative gap with the target. Table 9 gives the result of how team initiators would influence the consequences. The significant parameters indicate that adding one unit of a team position leads to 1.015 increase in the log amount pledged and 6.757 increase in the margin percentage, respectively. The probable reason for this is that, in a team, team members will collaborate with and supervise each other and ideas will be shared. This is also consistent with company status. The log amount of final pledges increases by 0.251 (Table 10) with a one-unit increase in company status, and this is statistically significant. This indicates that this title is beneficial to attracting more funds and could eventually improve funding outcomes. We also find that companies usually set a longer duration, and this may be due to the higher demand for capital to run an enterprise. This evidence is also further investigated by our later analysis of non-profit organizations. The last category is a specific project. Some initiators use their concrete product or content as their name instead of themselves. This action could give investors information and clarity about their ideas without needing to click on that project while browsing. Table 11 shows that putting a specific project name in a title could largely increase the margin percentage by 11.938 at a 99\% significance level. If someone is interested in an initiator's campaign from their first sight of the title, he or she would definitely enter their homepage, which accordingly attracts more donations. It also shows that campaigns appearing as a specific product tend to set fewer days raising money, leading to a higher possibility of success.

Table 8. U.S. individual results. This table reports results of regression analysis of the success, amount raised, duration, and margin (\%) variables when a U.S initiator is a team. We controlled for different variables. Table 3 defines all the variables.

\begin{tabular}{ccccc}
\hline \multirow{2}{*}{ Variables } & $\mathbf{( 1 )}$ & $\mathbf{( 2 )}$ & $\mathbf{( 3 )}$ & $\mathbf{( 4 )}$ \\
\cline { 2 - 5 } & Result & Lamount & Duration & Marginp \\
\hline Individual & $-0.429^{* * *}$ & $-0.211^{* * *}$ & -0.012 & $-4.138^{* * * *}$ \\
& $(0.074)$ & $(0.033)$ & $(0.231)$ & $(1.064)$ \\
Duration & $-0.023^{* * *}$ & $0.031^{* * *}$ & & $-0.129^{* * *}$ \\
& $(0.002)$ & $(0.001)$ & & $(0.032)$ \\
Updates & $0.295^{* * *}$ & -0.002 & $-0.086^{* * *}$ & 0.072 \\
& $(0.009)$ & $(0.002)$ & $(0.012)$ & $(0.057)$ \\
Word & -0.003 & -0.002 & $0.040^{* *}$ & -0.025 \\
& $(0.005)$ & $(0.002)$ & $(0.016)$ & $(0.073)$ \\
Laim & $-0.908^{* * *}$ & & $1.546^{* * *}$ & \\
& $(0.022)$ & & $(0.049)$ & \\
Backers & $0.031^{* * *}$ & $0.000^{* * *}$ & -0.000 & $0.003 * * *$ \\
& $(0.001)$ & $(0.000)$ & $(0.000)$ & $(0.000)$ \\
Nprojects & $0.000^{* * *}$ & $0.000^{* * *}$ & $-0.000^{* * *}$ & $-0.000 *$ \\
& $(0.000)$ & $(0.000)$ & $(0.000)$ & $(0.000)$ \\
Lpop & 0.011 & $0.020^{* * *}$ & -0.003 & 0.021 \\
& $(0.009)$ & $(0.004)$ & $(0.028)$ & $(0.127)$ \\
Constant & $6.555^{* * *}$ & $7.061^{* * *}$ & $19.101^{* * *}$ & $7.423^{* *}$ \\
& $(0.261)$ & $(0.107)$ & $(0.819)$ & $(3.463)$ \\
Industry effect & YES & YES & YES & YES \\
Observations & 19,849 & 19,849 & 19,849 & 19,849 \\
$R$-squared & & 0.172 & 0.061 & 0.015 \\
\hline Standard errors are in parentheses. ${ }^{*} p<0.1 ; * * p<0.05 ; * * * p<0.01$. \\
\hline
\end{tabular}


Table 9. U.S. team results. This table reports results of regression analysis of the success, amount raised, duration, and margin (\%) variables when a U.S initiator is a team. We controlled for different variables. Table 3 defines all the variables.

\begin{tabular}{|c|c|c|c|c|}
\hline \multirow{2}{*}{ Variables } & (1) & (2) & (3) & (4) \\
\hline & Result & Lamount & Duration & Marginp \\
\hline Team & $\begin{array}{l}-0.065 \\
(0.094)\end{array}$ & $\begin{array}{c}1.015^{* * *} \\
(0.072)\end{array}$ & $\begin{array}{c}0.327 \\
(0.351)\end{array}$ & $\begin{array}{c}6.757^{* * *} \\
(1.541)\end{array}$ \\
\hline Duration & $\begin{array}{c}-0.050^{* * * *} \\
(0.003)\end{array}$ & $\begin{array}{c}-0.015^{* * *} \\
(0.002)\end{array}$ & & $\begin{array}{c}-0.127^{* * *} \\
(0.032)\end{array}$ \\
\hline Updates & $\begin{array}{c}0.170 * * * \\
(0.007)\end{array}$ & $\begin{array}{c}0.171^{* * * *} \\
(0.003)\end{array}$ & $\begin{array}{l}-0.017 \\
(0.014)\end{array}$ & $\begin{array}{c}0.087 \\
(0.057)\end{array}$ \\
\hline Word & $\begin{array}{l}-0.003 \\
(0.005)\end{array}$ & $\begin{array}{c}-0.010 * * * \\
(0.004)\end{array}$ & $\begin{array}{l}0.034 * \\
(0.018)\end{array}$ & $\begin{array}{l}-0.029 \\
(0.073)\end{array}$ \\
\hline Laim & $\begin{array}{c}-0.860^{* * * *} \\
(0.021)\end{array}$ & & $\begin{array}{c}0.362 * * * \\
(0.039)\end{array}$ & \\
\hline Backers & $\begin{array}{l}0.000 \\
(0.000)\end{array}$ & $\begin{array}{c}0.000^{* * * *} \\
(0.000)\end{array}$ & $\begin{array}{c}0.000 \\
(0.000)\end{array}$ & $\begin{array}{c}0.003 * * * \\
(0.000)\end{array}$ \\
\hline Nprojects & $\begin{array}{c}-0.000^{* * * *} \\
(0.000)\end{array}$ & $\begin{array}{c}0.000^{* * *} \\
(0.000)\end{array}$ & $\begin{array}{l}0.000 \text { * } \\
(0.000)\end{array}$ & $\begin{array}{c}-0.000 * \\
(0.000)\end{array}$ \\
\hline Lpop & $\begin{array}{c}-0.023^{* * * *} \\
(0.009)\end{array}$ & $\begin{array}{c}0.030 * * * \\
(0.006)\end{array}$ & $\begin{array}{c}0.043 \\
(0.030)\end{array}$ & $\begin{array}{c}0.024 \\
(0.127)\end{array}$ \\
\hline Constant & $\begin{array}{c}-3.696^{* * * *} \\
(0.245)\end{array}$ & $\begin{array}{c}6.030^{* * *} \\
(0.161)\end{array}$ & $\begin{array}{c}32.461 * * * \\
(0.777)\end{array}$ & $\begin{array}{c}3.801 \\
(3.360)\end{array}$ \\
\hline Industry effect & Yes & Yes & Yes & Yes \\
\hline $\begin{array}{c}\text { Observations } \\
R \text {-squared }\end{array}$ & 15,819 & $\begin{array}{c}15,819 \\
0.377\end{array}$ & $\begin{array}{c}15,819 \\
0.023\end{array}$ & $\begin{array}{c}19,849 \\
0.015\end{array}$ \\
\hline
\end{tabular}

Table 10. U.S. company results. This table reports results of regression analysis of the success, amount raised, duration, and margin (\%) variables when a U.S. initiator is a company. We controlled for different variables. Table 3 defines all the variables.

\begin{tabular}{|c|c|c|c|c|}
\hline \multirow{2}{*}{ Variables } & (1) & (2) & (3) & (4) \\
\hline & Result & Lamount & Duration & Marginp \\
\hline Company & $\begin{array}{c}0.137 \\
(0.104)\end{array}$ & $\begin{array}{c}0.251^{* * *} \\
(0.044)\end{array}$ & $\begin{array}{c}0.692 * * \\
(0.309)\end{array}$ & $\begin{array}{l}-0.538 \\
(1.425)\end{array}$ \\
\hline Duration & $\begin{array}{c}-0.022 * * * \\
(0.002)\end{array}$ & $\begin{array}{c}-0.031^{* * *} \\
(0.001)\end{array}$ & & $\begin{array}{c}-0.128^{* * *} \\
(0.032)\end{array}$ \\
\hline Updates & $\begin{array}{c}0.293^{* * *} \\
(0.009)\end{array}$ & $\begin{array}{c}0.002 \\
(0.002)\end{array}$ & $\begin{array}{c}-0.088^{* * *} \\
(0.012)\end{array}$ & $\begin{array}{l}0.095 * \\
(0.057)\end{array}$ \\
\hline Word & $\begin{array}{l}-0.004 \\
(0.005)\end{array}$ & $\begin{array}{l}-0.001 \\
(0.002)\end{array}$ & $\begin{array}{l}0.040^{* *} \\
(0.016)\end{array}$ & $\begin{array}{l}-0.027 \\
(0.073)\end{array}$ \\
\hline Laim & $\begin{array}{c}-0.894^{* * *} \\
(0.022)\end{array}$ & & $\begin{array}{c}1.541^{* * *} \\
(0.049)\end{array}$ & \\
\hline Backers & $\begin{array}{c}0.031^{* * * *} \\
(0.001)\end{array}$ & $\begin{array}{c}0.000 * * * \\
(0.000)\end{array}$ & $\begin{array}{l}-0.000 \\
(0.000)\end{array}$ & $\begin{array}{c}0.003 * * * \\
(0.000)\end{array}$ \\
\hline Nprojects & $\begin{array}{c}0.000^{* * * *} \\
(0.000)\end{array}$ & $\begin{array}{c}0.000^{* * *} \\
(0.000)\end{array}$ & $\begin{array}{c}-0.000^{* * *} \\
(0.000)\end{array}$ & $\begin{array}{l}-0.000 \\
(0.000)\end{array}$ \\
\hline Lpop & $\begin{array}{c}0.010 \\
(0.009)\end{array}$ & $\begin{array}{c}0.021^{* * *} \\
(0.004)\end{array}$ & $\begin{array}{l}-0.004 \\
(0.027)\end{array}$ & $\begin{array}{c}0.030 \\
(0.127)\end{array}$ \\
\hline Constant & $\begin{array}{c}6.129 * * * \\
(0.248)\end{array}$ & $\begin{array}{c}6.859 * * * \\
(0.104)\end{array}$ & $\begin{array}{c}19.022^{* * *} \\
(0.795)\end{array}$ & $\begin{array}{c}4.224 \\
(3.367)\end{array}$ \\
\hline Observations & 19,849 & 19,849 & 19,849 & 19,849 \\
\hline$R$-squared & & 0.171 & 0.061 & 0.014 \\
\hline
\end{tabular}


Table 11. U.S. Project. This table reports results of regression analysis of the success, amount raised, duration, and margin (\%) variables when a U.S initiator starts a specific project. We controlled for different variables. Table 3 defines all the variables.

\begin{tabular}{ccccc}
\hline \multirow{2}{*}{ Variables } & $\mathbf{( 1 )}$ & $\mathbf{( 2 )}$ & $\mathbf{( 3 )}$ & $\mathbf{( 4 )}$ \\
\cline { 2 - 5 } & Result & Lamount & Duration & Marginp \\
\hline Project & 0.016 & 0.096 & $-1.569^{* *}$ & $11.938^{* * * *}$ \\
& $(0.265)$ & $(0.103)$ & $(0.722)$ & $(3.329)$ \\
Duration & $-0.022^{* * *}$ & $-0.031^{* * *}$ & & $-0.126^{* * *}$ \\
& $(0.002)$ & $(0.001)$ & & $(0.032)$ \\
Updates & $0.292^{* * *}$ & 0.001 & $-0.084^{* * *}$ & 0.080 \\
& $(0.009)$ & $(0.002)$ & $(0.012)$ & $(0.057)$ \\
Word & -0.003 & -0.002 & $0.040^{* *}$ & -0.027 \\
& $(0.005)$ & $(0.002)$ & $(0.016)$ & $(0.073)$ \\
Laim & $-0.890^{* * *}$ & & $1.546^{* * *}$ & \\
Backers & $(0.022)$ & & $(0.049)$ & \\
& $0.031^{* * *}$ & $0.000^{* * *}$ & -0.000 & $0.003 * * *$ \\
Nprojects & $(0.001)$ & $(0.000)$ & $(0.000)$ & $(0.000)$ \\
& $0.000^{* * *}$ & $0.000^{* * *}$ & $-0.000^{* * *}$ & $-0.000 *$ \\
Lpop & $(0.000)$ & $(0.000)$ & $(0.000)$ & $(0.000)$ \\
& 0.010 & $0.021^{* * *}$ & -0.003 & 0.029 \\
Constant & $(0.009)$ & $(0.004)$ & $(0.027)$ & $(0.127)$ \\
& $6.120^{* * *}$ & $6.892^{* * *}$ & $19.112^{* * * *}$ & 3.918 \\
Industry effect & $(0.248)$ & $(0.104)$ & $(0.795)$ & $(3.360)$ \\
Observations & YES & YE & YES & YES \\
R-squared & 19,849 & 19,849 & 19,849 & 19,849 \\
& & 0.170 & 0.061 & 0.015 \\
\hline
\end{tabular}

Standard errors are in parentheses. ${ }^{*} p<0.1 ;{ }^{* *} p<0.05 ;{ }^{* * *} p<0.01$.

To conclude, the name of the founder can affect final funding outcome to some extent. The nature of group and company status can win more trust from the public and specific projects can catch visitors' eyes quickly, both of which enhance the funding outcome.

\subsubsection{Individual Sample}

We further investigate the individual data to find out if the gender of founder and if the founder's use of his/her real name can increase their probability of success. In this analysis, the number of comments is controlled instead of backers. ${ }^{3}$ The results show that the more comments left on the projects' pages, the higher their probability of success (and also the higher pledged amounts for the project). Comments indicate how much attention browsers pay to the project, which also increase the "activeness" of its homepage. Based on the cluster effect, increasing numbers of comments attract more investors to participate in the project, thereby improving its funding outcomes.

Table 12 shows distinctions between the genders in the funding outcomes. In Column (1), as expected, there is a positive association between female and success, which means that with a one-unit increase in females, the log odds of success are expected to increase by 0.430 . Holding all other independent variables constant, the odds of success for females is $53.7 \%$ higher than that of odds of success for males. Column (2) also shows that on average, female initiators raise more funds than male initiators (0.311). These results are consistent with Gorbatai and Nelson (2015), who found that this outcome is partially explained by linguistic differences. They proved that positive emotion and inclusive language can lead to fundraising success; they also showed that women are more inclined to use language that is more positive, more vivid, and more inclusive. So this finding gives an explanation

3 These two variables are highly correlated. Therefore, we use only one of them in our analysis. 
of more crowdfunding success in females. Greenberg and Mollick (2015) also found that women outperform men in crowdfunding. As has already been shown, men are more likely to engage in unethical behavior (Betz et al. 2013), and women are more ethical than men in business situations (Ruegger and King 1992), meaning in online crowdfunding, women could probably gain more trust from investors through the internet if they perceive women to be more trustworthy. The predictor $(-0.228)$ in Column (3) illustrates that projects created by women usually have a shorter funding period than men, indicating that women set less time to raise money and reach their goal much faster, although this predictor is not statistically significant enough. Thus, our results provide the complete picture. Female entrepreneurs are more likely to succeed because they set more realistic goals and deadlines.

Table 12. Gender of initiators. This table reports results of regression analysis of the success, amount raised, duration, and margin (\%) variables when the initiator is an individual. We controlled for different variables. Table 3 defines all the variables.

\begin{tabular}{|c|c|c|c|c|}
\hline \multirow{2}{*}{ Variables } & (1) & (2) & (3) & (4) \\
\hline & Result & Lamount & Duration & Marginp \\
\hline Female & $\begin{array}{c}0.430 * * * \\
(0.056)\end{array}$ & $\begin{array}{c}0.311^{* * *} \\
(0.047)\end{array}$ & $\begin{array}{l}-0.228 \\
(0.206)\end{array}$ & $\begin{array}{l}-0.312 \\
(0.297)\end{array}$ \\
\hline Duration & $\begin{array}{c}-0.028^{* * *} \\
(0.002)\end{array}$ & $\begin{array}{c}-0.015^{* * *} \\
(0.002)\end{array}$ & & $\begin{array}{c}-0.031^{* * *} \\
(0.011)\end{array}$ \\
\hline Updates & $\begin{array}{c}0.405^{* * *} \\
(0.009)\end{array}$ & $\begin{array}{c}0.186^{* * *} \\
(0.003)\end{array}$ & $\begin{array}{c}-0.093^{* * *} \\
(0.015)\end{array}$ & $\begin{array}{c}0.089^{* * *} \\
(0.022)\end{array}$ \\
\hline Laim & $\begin{array}{c}-0.630^{* * *} \\
(0.019)\end{array}$ & & $\begin{array}{c}1.558^{* * *} \\
(0.053)\end{array}$ & \\
\hline Comments & $\begin{array}{c}0.089^{* * *} \\
(0.007)\end{array}$ & $\begin{array}{c}0.000^{* * *} \\
(0.000)\end{array}$ & $\begin{array}{l}-0.000 \\
(0.000)\end{array}$ & $\begin{array}{c}0.010^{* * *} \\
(0.000)\end{array}$ \\
\hline Nprojects & $\begin{array}{c}0.000^{* * *} \\
(0.000)\end{array}$ & $\begin{array}{c}0.000^{* * * *} \\
(0.000)\end{array}$ & $\begin{array}{c}-0.000^{* * *} \\
(0.000)\end{array}$ & $\begin{array}{l}-0.000 \\
(0.000)\end{array}$ \\
\hline Lpop & $\begin{array}{c}0.009 \\
(0.009)\end{array}$ & $\begin{array}{c}0.025^{* * *} \\
(0.007)\end{array}$ & $\begin{array}{l}-0.000 \\
(0.030)\end{array}$ & $\begin{array}{c}0.037 \\
(0.044)\end{array}$ \\
\hline Word & $\begin{array}{l}-0.003 \\
(0.005)\end{array}$ & $\begin{array}{c}-0.007^{*} \\
(0.004)\end{array}$ & $\begin{array}{c}0.050^{* * * *} \\
(0.017)\end{array}$ & $\begin{array}{l}-0.004 \\
(0.025)\end{array}$ \\
\hline Constant & $\begin{array}{c}4.608^{* * *} \\
(0.228)\end{array}$ & $\begin{array}{c}5.793 * * * \\
(0.187)\end{array}$ & $\begin{array}{c}19.033 * * * \\
(0.912)\end{array}$ & $\begin{array}{c}0.328 \\
(1.218)\end{array}$ \\
\hline Industry effect & Yes & Yes & Yes & Yes \\
\hline Observations & 16,723 & 12,964 & 16,723 & 16,723 \\
\hline$R$-squared & & 0.357 & 0.061 & 0.143 \\
\hline
\end{tabular}

Table 13 presents the impact of using a real name or being anonymous while crowdfunding. Surprisingly, we find that the funding results are positively correlated with being anonymous at the 99\% confidence level, which means projects' creators using a nickname could significantly increase their likelihood of final success in crowdfunding by $22.4 \%$. Additionally, this table exhibits that using anonymous names tends to attract larger amounts of money than using real names. Columns (2) and (4) provide significant positive and significant coefficients, which shows that compared with using real names, initiators using anonymous names could obtain more funding and exceed their goal by a larger gap. One possible explanation for this is that rational investors may be more concerned with the proposal itself, whether or not the proposal is interesting, worth investing in, and should be rewarded. This result shows that online crowdfunding seems fairer in comparison to traditional financing. Moreover, people do not know initiators personally so whether they are using their real names could matter less than the proposal itself. Another explanation could be the fact that anonymity protects the founders from the biases of the funders. This may lead to funders focusing more on the proposal and less on the founders. 
Table 13. Anonymous initiators. This table reports results of regression analysis of the success, amount raised, duration, and margin (\%) variables when the initiator is an anonymous individual. We controlled for different variables. Table 3 defines all the variables.

\begin{tabular}{ccccc}
\hline \multirow{2}{*}{ Variables } & $\mathbf{( 1 )}$ & $\mathbf{( 2 )}$ & $\mathbf{( 3 )}$ & $\mathbf{( 4 )}$ \\
\cline { 2 - 5 } & Result & Lamount & Duration & Marginp \\
\hline Anonymous & $0.202^{* * *}$ & $0.490^{* * *}$ & 0.266 & $5.855^{* * *}$ \\
& $(0.061)$ & $(0.050)$ & $(0.222)$ & $(2.001)$ \\
Duration & $-0.029^{* * *}$ & $-0.017^{* * *}$ & & -0.072 \\
& $(0.002)$ & $(0.002)$ & & $(0.062)$ \\
Updates & $0.416^{* * *}$ & $0.186^{* * *}$ & $-0.095^{* * *}$ & $0.823^{* * *}$ \\
& $(0.008)$ & $(0.003)$ & $(0.013)$ & $(0.119)$ \\
Laim & $-0.591^{* * *}$ & & $1.511^{* * *}$ & \\
& $(0.017)$ & & $(0.048)$ & \\
Comments & $0.051^{* * *}$ & 0.000 & -0.000 & $0.004^{* * *}$ \\
& $(0.004)$ & $(0.000)$ & $(0.000)$ & $(0.001)$ \\
Nprojects & $0.000^{* * *}$ & $0.000^{* * *}$ & $-0.000^{* * *}$ & -0.000 \\
& $(0.000)$ & $(0.000)$ & $(0.000)$ & $(0.000)$ \\
Lpop & 0.004 & $0.022^{* * *}$ & 0.001 & 0.194 \\
& $(0.008)$ & $(0.006)$ & $(0.028)$ & $(0.247)$ \\
Word & -0.003 & $-0.006^{*}$ & $0.054^{* * *}$ & -0.140 \\
& $(0.005)$ & $(0.004)$ & $(0.016)$ & $(0.141)$ \\
Constant & $4.623^{* * *}$ & $5.983^{* * *}$ & $19.261^{* * *}$ & 0.189 \\
& $(0.202)$ & $(0.169)$ & $(0.818)$ & $(6.786)$ \\
Observations & 20,093 & 15,811 & 20,093 & 20,093 \\
$R$-squared & & 0.371 & 0.060 & 0.006 \\
\hline Standard errors are in parentheses. ${ }^{*} p<0.1 ; * *$ & $p<0.05 ; * * * p<0.01$.
\end{tabular}

To summarize, we examine two dimensions of individual data: a gender dummy and an anonymous dummy. Our results confirm that women can raise money faster and more successfully than men through the internet. Anonymity can also help increase the odds of funding success and the total pledged amount.

\subsubsection{Company Sample}

For the company data, the sample consists of all the projects whose creator is in the form of a company. We focus on the relationship between the non-profit organization and crowdfunding consequences. In this data sample of 1837 company projects, only 105 projects were launched by non-profitable organizations. Belleflamme et al. $(2010$, p. 2) pointed out that "non-profit organizations tend to be more successful in using crowdfunding" as non-monetary incentives win more trust. So, we expect to find the positive impact from the status of non-profit. In this regression, the number of comments is also used instead of backers. However, we further extend their research and investigate the relationship between the funding target and duration of the projects initiated by non-profit organizations.

Table 14 summarizes the comparison between non-profit organizations and for-profit companies. Column (1) illustrates that the non-profit organizational form significantly increases the probability of funding success than other company forms (0.692). Non-profit organizations are $99.8 \%$ [exp (0.692)] more likely to achieve their goal than are profitable companies at the $99 \%$ confidence level. According to Column (2), with a one-unit increase in non-profit organizations, the logarithm of total amount being raised is expected to increase by 0.415 . The limited monetary incentives of NPOs appeal to donations more easily. These results are consistent with contract failure theory, which was first proposed by Henry Hansmann (1980), which suggested that non-profit enterprises could gain more trust due to their focus on public benefit rather than on monetary profits, thereby absorbing more outside funds. However, Columns (3) and (4) show that this form will set a longer time than other forms of founders to reach the fundraising goal and there is a negative gap from the goal set. This phenomenon is 
possibly accounted for by their major monetary demand to operate their whole organization, so the target amount is set to be large, thereby causing a longer duration and a negative margin percentage.

Table 14. Organization results. This table reports the relationship between geographical effects and the success of a project. We control for different variables. Table 3 defines all the variables.

\begin{tabular}{ccccc}
\hline \multirow{2}{*}{ Variables } & $\mathbf{( 1 )}$ & $\mathbf{( 2 )}$ & $\mathbf{( 3 )}$ & $\mathbf{( 4 )}$ \\
\cline { 2 - 5 } & Result & Lamount & Duration & Marginp \\
\hline Org & $0.692^{* * *}$ & $0.415^{*}$ & 1.737 & -0.802 \\
& $(0.267)$ & $(0.235)$ & $(1.136)$ & $(2.390)$ \\
Duration & $-0.021^{* * *}$ & $-0.014^{* * *}$ & & $-0.097^{* *}$ \\
& $(0.007)$ & $(0.005)$ & & $(0.048)$ \\
Updates & $0.320^{* * *}$ & $0.116^{* * *}$ & $-0.090^{* * *}$ & $0.090^{*}$ \\
& $(0.020)$ & $(0.005)$ & $(0.024)$ & $(0.051)$ \\
Word & -0.003 & 0.011 & -0.033 & -0.035 \\
& $(0.016)$ & $(0.011)$ & $(0.054)$ & $(0.113)$ \\
Laim & $-0.686^{* * *}$ & & $1.393 * * *$ & \\
Comments & $(0.058)$ & & $(0.165)$ & \\
& $0.010^{* * *}$ & $0.000^{* *}$ & -0.000 & $0.001 *$ \\
Nprojects & $(0.002)$ & $(0.000)$ & $(0.000)$ & $(0.000)$ \\
& $1.359^{* * *}$ & $1.842^{* * *}$ & -0.665 & $-2.302 *$ \\
Lpop & $(0.208)$ & $(0.143)$ & $(0.668)$ & $(1.392)$ \\
& -0.004 & $0.059^{* * *}$ & 0.044 & -0.253 \\
Constant & $(0.026)$ & $(0.018)$ & $(0.093)$ & $(0.206)$ \\
& $5.330^{* * *}$ & $5.551^{* * *}$ & $19.976^{* * *}$ & 4.996 \\
Industry effect & $(0.631)$ & $(0.357)$ & $(2.076)$ & $(3.663)$ \\
Observations & Yes & Yes & Yes & Yes \\
R-squared & 1835 & 1679 & 1835 & 1835 \\
& & 0.397 & 0.069 & 0.020 \\
\hline
\end{tabular}

Standard errors are in parentheses. ${ }^{*} p<0.1 ;{ }^{* *} p<0.05 ;{ }^{* * *} p<0.01$.

\subsection{Robustness Tests}

Our study finds that female initiators are more likely to succeed in raising money for their projects. However, our results could have been driven by traditional industries in which women historically have been more successful. To counter this argument, we rerun our baseline gender model for all fifteen industries. Table 15 reports these results. The coefficient for females is positive for all the models, except for the crafts industry. However, it is not significant at conventional levels of significance for this industry. Anna et al. (2000) consider this to be a traditional industry for women entrepreneurs. This study shows that female entrepreneurs are significantly more successful than are men in financing their projects in non-traditional industries, such as comics, film/video, publishing, and technology. These industries traditionally have been dominated by male entrepreneurs. Our study shows that, at least in getting financing online, women are more successful than their male counterparts in these industries. Thus, another novel contribution of our research is to show that female entrepreneurs are more capable in succeeding in almost all the industries compared with their male counterparts. Therefore, we can say that female entrepreneurs are breaking the glass ceiling in different industries online. 
Table 15. Gender, success, and industry. This table reports the relationship between gender and success by industry. We control for different variables. Table 3 defines all the variables. ${ }^{*} p<0.1 ; * * 0<0.05 ;{ }^{* * *} p<0.01$.

\begin{tabular}{|c|c|c|c|c|c|c|c|c|c|c|c|c|c|c|c|}
\hline Variable & Art & Comics & Crafts & Dance & Design & Theater & Fashion & Film/Video & Food & Games & Journalism & Music & Photography & Publishing & Technology \\
\hline \multirow[t]{2}{*}{ Duration } & $-0.023 * * *$ & $-0.035^{* *}$ & $-0.029 *$ & $-0.044^{* *}$ & $-0.025^{* *}$ & $-0.028^{* *}$ & $-0.021 *$ & $-0.037^{* * *}$ & $-0.037^{* * *}$ & $-0.024 * *$ & -0.016 & $-0.023^{* * *}$ & $-0.023 *$ & $-0.021^{* * *}$ & 0.000 \\
\hline & -0.007 & -0.014 & -0.016 & -0.018 & -0.01 & -0.013 & -0.011 & -0.006 & -0.009 & -0.012 & -0.014 & -0.006 & -0.012 & -0.006 & -0.01 \\
\hline \multirow[t]{2}{*}{ Female } & $0.536^{* * *}$ & $0.690 *$ & -0.064 & 0.311 & 0.312 & 0.15 & $0.465^{* *}$ & $0.918^{* * *}$ & 0.198 & 0.516 & 0.216 & 0.278 * & 0.105 & 0.290 ** & $0.751^{* * * *}$ \\
\hline & -0.152 & -0.402 & -0.294 & -0.421 & -0.244 & -0.295 & -0.213 & -0.135 & -0.19 & -0.353 & -0.381 & -0.151 & -0.256 & -0.139 & -0.285 \\
\hline \multirow[t]{2}{*}{ Updates } & $0.454^{* * *}$ & $0.277^{* * *}$ & $0.573^{* * *}$ & $0.408^{* * *}$ & $0.427^{* * *}$ & $0.360^{* * *}$ & $0.431^{* * *}$ & $0.343^{* * *}$ & $0.456^{* * *}$ & $0.280^{* * *}$ & $0.523 * * *$ & $0.545^{* * *}$ & $0.283 * * *$ & $0.349^{* * *}$ & $0.392^{* * *}$ \\
\hline & -0.032 & -0.03 & -0.06 & -0.101 & -0.041 & -0.058 & -0.039 & -0.019 & -0.035 & -0.027 & -0.074 & -0.032 & -0.039 & -0.022 & -0.034 \\
\hline \multirow[t]{2}{*}{ Laim } & $-0.494^{* * *}$ & $-0.972 * * *$ & $-0.894^{* * *}$ & $-0.468^{* * *}$ & $-0.717^{* * *}$ & $-0.801 * * *$ & $-0.576^{* * *}$ & $-0.724^{* * *}$ & $-0.591^{* * *}$ & $-0.889^{* * *}$ & $-0.592 * * *$ & $-0.601 * * *$ & $-0.542^{* * *}$ & $-0.611^{* * *}$ & $-0.918^{* * *}$ \\
\hline & -0.05 & -0.135 & -0.111 & -0.147 & -0.082 & -0.135 & -0.075 & -0.048 & -0.052 & -0.087 & -0.117 & -0.054 & -0.087 & -0.053 & -0.079 \\
\hline \multirow[t]{2}{*}{ Comments } & $0.137^{* * *}$ & $0.092 * * *$ & $0.351^{* * *}$ & $0.605^{* *}$ & $0.058^{* * *}$ & $2.076^{* * *}$ & $0.223^{* * *}$ & $0.135^{* * *}$ & $0.196^{* * *}$ & $0.053^{* * *}$ & 0.332 ** & $0.667^{* * *}$ & $0.391^{* * *}$ & $0.117^{* * *}$ & $0.091^{* * *}$ \\
\hline & -0.035 & -0.023 & -0.065 & -0.253 & -0.012 & -0.395 & -0.041 & -0.026 & -0.035 & -0.008 & -0.13 & -0.059 & -0.082 & -0.026 & -0.015 \\
\hline \multirow[t]{2}{*}{ NProjects } & $0.000 * * *$ & 0 & $0.000 *$ & 0 & 0 & $0.000^{* * *}$ & $0.000 * *$ & $0.000^{* * * *}$ & $0.000 * * *$ & 0 & $0.000^{* * *}$ & $0.000^{* * *}$ & 0.000 ** & 0 & 0 \\
\hline & 0.000 & 0.00 & 0.000 & 0.000 & 0.000 & 0.000 & 0.000 & 0.000 & 0.000 & 0.000 & 0.000 & 0.000 & 0.000 & 0 & 0 \\
\hline \multirow[t]{2}{*}{ Constant } & $1.800 * * *$ & $6.554^{* * *}$ & $3.497 * * *$ & $3.279 * * *$ & $4.103^{* * *}$ & $5.254^{* * *}$ & $1.744^{* * *}$ & $4.683^{* * * *}$ & $2.621^{* * *}$ & $4.359^{* * *}$ & 1.491 * & $3.045^{* * *}$ & $2.261^{* * *}$ & $3.099 * * *$ & $3.760^{* * *}$ \\
\hline & -0.375 & -1.048 & -0.791 & -1.177 & -0.623 & -0.971 & -0.615 & -0.38 & -0.434 & -0.649 & -0.872 & -0.422 & -0.683 & -0.433 & -0.637 \\
\hline Obs. & 1556 & 571 & 968 & 195 & 964 & 388 & 1414 & 2564 & 1777 & 1208 & 543 & 2315 & 716 & 2114 & 2222 \\
\hline
\end{tabular}


To the best of our knowledge, no study has investigated the relationship between gender and total failure in raising money through crowdsourcing. Table 16 reports these results. The results show that female entrepreneurs are less likely to face a situation in which no one contributes toward their projects. This indicates that female entrepreneurs are less likely to ask for money for frivolous projects. In Table 16, we also report the results for the relationship between gender and projects that get more funding than was asked for. Interestingly, women are less likely to end up with projects that get more funding than was asked for. This shows that women set a realistic "Aim" when they ask for financing. It also shows that they set the "Aim" that meets the expectation of the contributors. As women are less likely to have these two extreme outcomes, our results show that women are more risk averse than men in setting their target amounts.

Table 16. Relationship between gender, total failure, and more than aim. Table 3 defines all the variables.

\begin{tabular}{ccc}
\hline \multirow{2}{*}{ Variable } & $\mathbf{( 1 )}$ & $\mathbf{( 2 )}$ \\
\cline { 2 - 3 } & Total Failure & More Than Aim \\
\hline Female & $-0.128^{* * *}$ & $-0.017^{* * *}$ \\
Duration & $(0.049)$ & $(0.004)$ \\
& 0.001 & $-0.001^{* * *}$ \\
Updates & $(0.002)$ & $(0.000)$ \\
& $-0.607^{* * * *}$ & $0.011^{* * *}$ \\
Laim & $(0.029)$ & $(0.000)$ \\
& $0.069^{* * *}$ & \\
Comments & $(0.012)$ & $0.000^{* * * *}$ \\
& $-2.044^{* * *}$ & $(0.000)$ \\
NProjects & $(0.132)$ & 0.000 \\
& $-0.000^{* * *}$ & $(0.000)$ \\
Lpop & $(0.000)$ & $0.001 * * *$ \\
& 0.005 & $(0.001)$ \\
Constant & $(0.007)$ & 0.019 \\
& $-1.366^{* * *}$ & $(0.015)$ \\
Observations & $(0.218)$ & 16,723 \\
Adjusted $R$-squared & 16,723 & 0.162 \\
\hline Standard errors are in parentheses. ${ }^{*} p<0.1 ; * * p<0.05 ; * * * p<0.01$.
\end{tabular}

These results show that crowdsourcing has, to some extent, leveled the playing field for women. They also show the reasons behind the success of female entrepreneurs in all industries. Women are less likely to set frivolous and unrealistic goals.

\section{Discussion}

In this section, we compare our results with existing studies in crowdfunding. ${ }^{4}$ Even though some of our results are similar to different studies investigating equity crowdfunding, others are different and novel. Vismara (2018a) suggests that equity crowdfunding and donation based crowdfunding differ in important aspects. The theoretical foundations of donation based funding are altruism and charitable giving. However, investors motivated by financial return are more likely to be attracted to equity crowdfunding. Regulators are also concerned about elevated possibility of fraud in equity crowdfunding markets (Hornuf and Schwienbacher 2017). Signori and Vismara (2018) suggest that one reason for the existence of potential fraud is lack of repeated interaction between investors and firms raising capital through equity crowdfunding. In our study, the number of projects initiated by the same initiator can be seen as a repeated interaction. In other words, if the initiator has previously raised

4 We are thankful to an anonymous referee for suggesting the addition of this section. 
money for other projects, this may indicate to the potential investors that the probability of fraud is lower. Allison et al. (2015) provide a hypothetical example of controlling environment ${ }^{5}$. They suggest that setting a time limit and a reward is more likely to motivate individuals. In our study, timing plays an important role. We find that a shorter time limit is associated with success of a project. This confirms the intuitive urgency suggested in the hypothetical example provided by Allison et al. (2015).

Vismara (2016) emphasizes the key role played by signaling in raising capital in different financial markets. In our study, signaling good quality through different cues plays an important role in the success of different projects. We find that a very ambitious aim is less likely to succeed. A very ambitious goal may suggest that the project is not credible or the initiators will not have the ability to complete such a project successfully. We also find that having a large number of backers leads to a higher probability of success. This may be a reflection of the large social network of the initiators. Vismara (2018b) summarizes that the effect of the number of backers on probability of success of a campaign has not been consistent across different studies.

Updates provide important feedback to investors. Information asymmetry plays an important role in determining the outcome of a crowdfunding campaign (Vismara 2018a). Updates reduce this information asymmetry. We find a positive relationship between number of updates and the probability of success. In the context of crowdfunding, Block et al. (2018) also find a positive relationship between success of equity crowdfunding and number of updates.

We find that campaigns initiated by individuals are less successful than the ones initiated by teams or companies. Ahlers et al. (2015) find that the number and quality of management team have a positive effect on the probability of success in case of equity crowdfunding. We find a similar result, as teams and companies may signal that they possess a diversity of expertise and will be able to successfully carry out a project. We also find that companies are able to raise significantly higher amounts of capital than individuals.

Different studies have investigated the relationship between probability of success in equity crowdfunding and social capital (Pierrakis 2019; Ahlers et al. 2015). An important result of our study is the finding that anonymity does not negatively affect the probability of success of a project. As a matter of fact, we find that anonymity has a positive relationship with the probability of success. Prima facie, this is a surprising finding. However, this is consistent with Ahlers et al. (2015) who find that social capital has no impact on funding success for equity crowdfunding. Our finding seems to be rooted in human behavior towards strangers. Gintis et al. (2008) and Price (2008) find that human beings behave ethically and prosocially towards to strangers and this behavior is rooted in evolution. To the best of our knowledge, this is the first study to document positive relationship between anonymity and the probability of success in the context of crowdfunding.

The effect of gender on the success of crowdfunding campaigns has been previously investigated. Malaga et al. (2018) find that gender is not a significant factor in raising funds in equity crowdfunding. However, we find that females are more successful in raising capital in our study. Our finding is consistent with findings of Gorbatai and Nelson (2015) and Greenberg and Mollick (2015). However, our study provides important new insights. We find that women are more successful than men because they set realistic targets. They are less likely to experience complete failure. They also set lower time limit to raise capital. In other words, women use controlling (Allison et al. 2015) and signaling quality (Connelly et al. 2011) better than men. Therefore, women signal quality through setting realistic goals and nudge investors to take prompt action by setting a lower time limit for the project. We also find that women are more successful in raising capital not only in industries traditionally dominated by them but also in non-traditional industries (e.g., comics, film/video, publishing and technology) dominated by men. This is another novel finding of our study.

5 Allison et al. (2015) suggest that asking participants to "go run one lap around the track" is less controlling than asking them to "go run one lap around the track in two minutes or less ... " (p. 57). 
We also find that non-profit companies are more successful in raising capital than for-profit ones. Vismara (2019) finds that investors in equity crowdfunding do not prefer sustainable investments. Investors participating in equity crowdfunding campaigns are more likely to have profit maximization as their primary motive. However, Kickstarter does not allow equity crowdfunding, thus investors in our study are more likely to exhibit altruistic motives.

\section{Conclusions}

This paper has provided both a broad and detailed analysis of the determinants of crowdfunding success through three main aspects: the general characteristics of crowdfunding campaigns, the classifications of projects' initiators, and geographic and country effects. The findings of this paper can give a more empirical method to new entrepreneurs who want to seek financing from online crowdfunding. A realistic funding goal is important to projects' success. A high funding goal will lead to lower odds of success for a project. A clear and brief description of the project, frequent updates, interactions with donors, and more backers' support will enhance a project's potential for success. Projects that have a longer duration and initiators that have already created many projects will have a lower chance to succeed in crowdfunding.

We also find that male founders are more likely to set up a crowdfunding project; the number of projects initiated by male founders is 2 times that of female founders. However, the odds of success of female founders is significantly higher than that of male ones, which indicates identifying as a woman will raise the rate of success in online crowdfunding. A novel contribution of our research is to show that female entrepreneurs are more capable in succeeding in almost all the fifteen industries compared with their male counterparts. We also show that women do so by using controlling (Allison et al. 2015) and signaling (Connelly et al. 2011) better than men. In other words, they set realistic targets and set lower time limit to meet these targets. This conveys quality (entrepreneurs are not trying to take advantage of the generosity of the strangers) and makes investors take action promptly. For individual founders, whether or not they use their real name will not increase their odds of success; the thing that really matters is the project itself and not who created it. This is consistent with Homo sapiens showing ethical and altruistic behavior towards strangers without expecting anything in return (Price 2008 and Gintis et al. 2008). It is also suggested that raising money in a form of a team, a company, or directly indicating a specific product is also beneficial to crowdfunding outcomes. In contrast, individuals have a lower chance to succeed in crowdfunding. Particularly, people are more likely to donate money when a project is not profit-oriented. Therefore, our results confirm the findings of evolutionary biologists that human beings take pleasure in prosocial, ethical and altruistic behaviour and feel pain when they behave otherwise (Gintis et al. 2008). Finally, in line with former research, the geographic homophily is also an important factor, a larger city population is in lined with a higher success probability. This is the first paper to analyze the anonymity problem in crowdfunding. In addition, the initiator type is also thoroughly analyzed for the first time in the empirical research. This paper comprehensively covers general characteristics and geographic effects.

We believe that our holistic approach provides improved and novel insights than previous studies. However, there are important shortcomings of our study. Kickstarter imposes certain restrictions on the initiators. It stipulates that only projects that create something (product or service) and share a product or service that can be posted on its platform. An equity interest cannot be offered in the project and initiators cannot raise money as a charitable donation. Thus, our results are limited by the types of projects initiated within these restrictions.

For future research, some aspects discussed in our paper need to be further studied. This paper only takes static factors into consideration without dynamic factors. For example, the changes of these factors with a timeline could significantly affect funding results. Finally, a longer time period of projects could be studied, as opposed to the 6-month duration studied in our paper.

Author Contributions: Both authors contributed equally to the article. All authors have read and agreed to the published version of the manuscript. 
Funding: The research received no external funding.

Acknowledgments: We are thankful to the guest editors, Douglas Cumming and Sofia Johan, and two anonymous referees for excellent comments and suggestions. We are also thankful to participants at 10th International Research Meeting in Business and Management and 2nd International Conference on Digital, Innovation, Entrepreneurship \& Finance for helpful comments. All errors are ours.

Conflicts of Interest: The authors declare no conflict of interest.

\section{References}

Agrawal, Ajay K., Christian Catalini, and Avi Goldfarb. 2011. The Geography of Crowdfunding. National Bureau of Economic Research Working Paper (No. w16820). Cambridge: National Bureau of Economic Research.

Ahlers, Gerrit K., Douglas Cumming, Christina Günther, and Denis Schweizer. 2015. Signaling in equity crowdfunding. Entrepreneurship Theory and Practice 39: 955-80.

Allison, Thomas H., Blakley C. Davis, Jeremy C. Short, and Justin W. Webb. 2015. Crowdfunding in a prosocial microlending environment: Examining the role of intrinsic versus extrinsic cues. Entrepreneurship Theory and Practice 39: 53-73.

Anna, Alexandra L., Gaylen N. Chandler, Erik Jansen, and Neal P. Mero. 2000. Women business owners in traditional and non-traditional industries. Journal of Business Venturing 15: 279-303.

Ba, Sulin. 2001. Establishing online trust through a community responsibility system. Decision Support Systems 31: 323-36.

Beier, Michael, and Kerstin Wagner. 2015. Crowdfunding Success: A Perspective from Social Media and e-Commerce. Available online: https://aisel.aisnet.org/icis2015/proceedings/eBizeGov/11/ (accessed on 27 March 2018).

Belleflamme, Paul, Thomas Lambert, and Armin Schwienbacher. 2010. Crowdfunding: An industrial organization perspective. Paper presented at the Workshop Digital Business Models: Understanding Strategies, Paris, France, June 25-26; pp. 25-26.

Belleflamme, Paul, Thomas Lambert, and Armin Schwienbacher. 2013. Individual crowdfunding practices. Venture Capital 15: 313-33.

Belleflamme, Paul, Thomas Lambert, and Armin Schwienbacher. 2014. Crowdfunding: Tapping the right crowd. Journal of Business Venturing 29: 585-609.

Betz, Michael, Lenahan O'Connell, and Jon M. Shepard. 2013. Gender differences in proclivity for unethical behavior. In Citation Classics from the Journal of Business Ethics. Dordrecht: Springer, pp. 427-32.

Block, Jörn, Lars Hornuf, and Alexandra Moritz. 2018. Which updates during an equity crowdfunding campaign increase crowd participation? Small Business Economics 50: 3-27.

Carvajal, Miguel, José A. García-Avilés, and José L. González. 2012. Crowdfunding and non-profit media: The emergence of new models for public interest journalism. Journalism Practice 6: 638-47.

Chaudhuri, Ananish, Tirnud Paichayontvijit, and Lifeng Shen. 2013. Gender differences in trust and trustworthiness: Individuals, single sex and mixed sex groups. Journal of Economic Psychology 34: 181-94.

Connelly, Brian L., S. Trevis Certo, R. Duane Ireland, and Christopher R. Reutzel. 2011. Signaling theory: A review and assessment. Journal of Management 37: 39-67.

Cordova, Alessandro, Johanna Dolci, and Gianfranco Gianfrate. 2015. The determinants of crowdfunding success: Evidence from technology projects. Procedia-Social and Behavioral Sciences 181: 115-24.

Crosetto, Paolo, and Tobias Regner. 2014. Crowdfunding: Determinants of Success and Funding Dynamics. Jena Economic Research Papers No. 2014-035. Jena: Friedrich-Schiller-University.

Cumming, Douglas J., Gaël Leboeuf, and Armin Schwienbacher. 2015. Crowdfunding models: Keep-it-all vs. all-or-nothing. Financial Management. [CrossRef]

Frydrych, Denis, Adam J. Bock, Tony Kinder, and Benjamin Koeck. 2014. Exploring entrepreneurial legitimacy in reward-based crowdfunding. Venture Capital 16: 247-69.

Gintis, Herbert, Joseph Henrich, Samuel Bowles, Robert Boyd, and Ernst Fehr. 2008. Strong reciprocity and the roots of human morality. Social Justice Research 21: 241-53.

Golesorkhi, Banu. 2006. Gender differences and similarities in judgments of trustworthiness. Women in Management Review 21: 195-210.

Gorbatai, Andreea Daniela, and Laura Nelson. 2015. Gender and the language of crowdfunding. In Acadeour of Management Proceedings. Briarcliff Manor: Acadeour of Management, vol. 2015, No. 1. p. 15785. 
Greenberg, Jason, and Ethan Mollick. 2015. Leaning in or leaning on? Gender, homophily, and activism in crowdfunding. In Acadeour of Management Proceedings. Pennsylvania: ScholarlyCommons.

Guenther, Christina, Sofia Johan, and Denis Schweizer. 2018. Is the crowd sensitive to distance?-How investment decisions differ by investor type. Small Business Economics 50: 289-305.

Hansmann, Henry B. 1980. The role of nonprofit enterprise. Yale Law Journal 89: 835-901.

Hörisch, Jacob. 2015. Crowdfunding for environmental ventures: An empirical analysis of the influence of environmental orientation on the success of crowdfunding initiatives. Journal of Cleaner Production 107: 636-45.

Hornuf, Lars, and Armin Schwienbacher. 2017. Should securities regulation promote equity crowdfunding? Small Business Economics 49: 579-93.

Kuppuswamy, Venkat, and Barry L. Bayus. 2018. Crowdfunding creative ideas: The dynamics of project backers. In The Economics of Crowdfunding. Cham: Palgrave Macmillan, pp. 151-82.

Howe, Jeff. 2006. The Rise of Crowdfunding. Wired. June 1. Available online: https://www.wired.com/2006/06/ crowds/ (accessed on 27 March 2018).

Lambert, Thomas, and Armin Schwienbacher. 2010. An Empirical Analysis of Crowdfunding. Social Science Research Network 1578175: 1-23.

Li, Yan, Vineeth Rakesh, and Chandan K. Reddy. 2016. Project success prediction in crowdfunding environments. Paper presented at the Ninth ACM International Conference on Web Search and Data Mining, San Francisco, CA, USA, February 22-25; New York: ACM, pp. 247-56.

Malaga, Ross, Stanislav Mamonov, and Janet Rosenblum. 2018. Gender difference in equity crowdfunding: An exploratory analysis. International Journal of Gender and Entrepreneurship 10: 332-43.

Mason, Colin. 2007. Venture capital: A geographical perspective. In Handbook of Research on Venture Capital. Cheltenham: Edward Elgar, pp. 86-112.

Mollick, Ethan. 2014. The dynamics of crowdfunding: An exploratory study. Journal of Business Venturing 29: 1-16.

Muller, Michael, Werner Geyer, Todd Soule, and John Wafer. 2014. Geographical and organizational distances in enterprise crowdfunding. Paper presented at the 17th ACM Conference on Computer Supported Cooperative Work \& Social Computing, Baltimore, MD, USA, February 15-19; New York: ACM, pp. 778-89.

Nanda, Ramana, and Tarun Khanna. 2010. Diasporas and domestic entrepreneurs: Evidence from the Indian software industry. Journal of Economics \& Management Strategy 19: 991-1012.

Pierrakis, Yannis. 2019. How Do Social Capital and Outsourcing Building Strategies of Ventures Influence Their Success of Initial Coin Offerings (ICOs)? Working Paper. Available online: https://dif2019.sciencesconf.org/data/pages/ AGENDA_UPDATE_3.pdf (accessed on 27 March 2018).

Price, Michael E. 2008. The resurrection of group selection as a theory of human cooperation. Social Justice Research 21: 228-40.

Read, Andy. 2013. Crowdfunding: An Empirical and Theoretical Model of Non-Profit Support. Working Paper. Tacoma: Sound Ideas.

Robertson, Emily, and Rossitza B. Wooster. 2015. Crowdfunding as a Social Movement: The Determinants of Success in Kickstarter Campaigns. Working Paper. Available online: https://papers.ssrn.com/sol3/papers.cfm?abstract_ id=2631320 (accessed on 27 March 2018).

Ruegger, Durwood, and Ernest W. King. 1992. A study of the effect of age and gender upon student business ethics. Journal of Business Ethics 11: 179-86.

Signori, Andrea, and Silvio Vismara. 2018. Does success bring success? The post-offering lives of equity-crowdfunded firms. Journal of Corporate Finance 50: 575-91.

Solomon, Jacob, Wenjuan Ma, and Rick Wash. 2015. Don't wait!: How timing affects coordination of crowdfunding donations. Paper presented at the 18th ACM Conference on Computer Supported Cooperative Work \& Social Computing, Vancouver, BC, Canada, March 14-18; New York: ACM, pp. 547-56.

Song, Aejin, Hong-in Lee, Minsam Ko, and Uichin Lee. 2015. Every Little Helps: Understanding Donor Behavior in a Crowdfunding Platform for Non-profits. Paper presented at the 33rd Annual ACM Conference Extended Abstracts on Human Factors in Computing Systems, Seoul, Korea, April 18-23; New York: ACM, pp. 1103-8.

Vachelard, Julien, Thaise Gambarra-Soares, Gabriela Augustini, Pablo Riul, and Vinicius Maracaja-Coutinho. 2016. A guide to scientific crowdfunding. PLoS Biology 14: e1002373.

Vismara, Silvio. 2016. Equity retention and social network theory in equity crowdfunding. Small Business Economics 46: 579-90. 
Vismara, Silvio. 2018a. Information cascades among investors in equity crowdfunding. Entrepreneurship Theory and Practice 3: 467-97.

Vismara, Silvio. 2018b. Signaling to overcome inefficiencies in crowdfunding markets. In The Economics of Crowdfunding. Cham: Palgrave Macmillan, pp. 29-56.

Vismara, Silvio. 2019. Sustainability in equity crowdfunding. Technological Forecasting and Social Change 141: 98-106.

Xu, Anbang, Xiao Yang, Huaming Rao, Wai-Tat Fu, Shih-Wen Huang, and Brian P. Bailey. 2014. Show me the money!: An analysis of project updates during crowdfunding campaigns. Paper presented at the SIGCHwe Conference on Human Factors in Computing Systems, Toronto, ON, Canada, April 26-May 1; New York: ACM, pp. 591-600.

Zhang, Haisu, and Weizhi Chen. 2019. Crowdfunding technological innovations: Interaction between consumer benefits and rewards. Technovation 84: 11-20.

Zhou, Mi Jamie, Baozhou Lu, Weiguo Patrick Fan, and G. Alan Wang. 2016. Project description and crowdfunding success: An exploratory study. Information Systems Frontiers 20: 1-16.

(C) 2020 by the authors. Licensee MDPI, Basel, Switzerland. This article is an open access article distributed under the terms and conditions of the Creative Commons Attribution (CC BY) license (http://creativecommons.org/licenses/by/4.0/). 